\title{
Pharmacophore Models and Pharmacophore-Based Virtual Screening: Concepts and Applications Exemplified on Hydroxysteroid Dehydrogenases
}

\author{
Teresa Kaserer ${ }^{1,+}$, Katharina R. Beck ${ }^{2,+}$, Muhammad Akram ${ }^{1}$, Alex Odermatt ${ }^{2, *}$ and \\ Daniela Schuster ${ }^{1, *}$
}

Received: 19 November 2015; Accepted: 9 December 2015; Published: 19 December 2015

Academic Editor: Peter Willett

1 Institute of Pharmacy/Pharmaceutical Chemistry and Center for Molecular Biosciences Innsbruck (CMBI), Computer Aided Molecular Design Group, University of Innsbruck, Innrain 80/82, 6020 Innsbruck, Austria; Teresa.Kaserer@uibk.ac.at (T.K.); Muhammad.Akram@uibk.ac.at (M.A.)

2 Swiss Center for Applied Human Toxicology and Division of Molecular and Systems Toxicology, Department of Pharmaceutical Sciences, Pharmacenter, University of Basel, Klingelbergstrasse 50, 4056 Basel, Switzerland; Katharina.Beck@unibas.ch

* Correspondence: Alex.Odermatt@unibas.ch (A.O.); Daniela.Schuster@uibk.ac.at (D.S.); Tel.: +41-61-267-1530 (A.O.); +43-512-507-58253 (D.S.); Fax: +41-61-267-1515 (A.O.); +43-512-507-58299 (D.S.)

+ These authors contributed equally to this work.

\begin{abstract}
Computational methods are well-established tools in the drug discovery process and can be employed for a variety of tasks. Common applications include lead identification and scaffold hopping, as well as lead optimization by structure-activity relationship analysis and selectivity profiling. In addition, compound-target interactions associated with potentially harmful effects can be identified and investigated. This review focuses on pharmacophore-based virtual screening campaigns specifically addressing the target class of hydroxysteroid dehydrogenases. Many members of this enzyme family are associated with specific pathological conditions, and pharmacological modulation of their activity may represent promising therapeutic strategies. On the other hand, unintended interference with their biological functions, e.g., upon inhibition by xenobiotics, can disrupt steroid hormone-mediated effects, thereby contributing to the development and progression of major diseases. Besides a general introduction to pharmacophore modeling and pharmacophore-based virtual screening, exemplary case studies from the field of short-chain dehydrogenase/reductase (SDR) research are presented. These success stories highlight the suitability of pharmacophore modeling for the various application fields and suggest its application also in futures studies.
\end{abstract}

Keywords: pharmacophore; virtual screening; ligand protein interactions; hydroxysteroid dehydrogenase; oxidoreductase

\section{Introduction}

\section{Pharmacophore Modeling}

The concept of "pharmacophores" dates back to the late 19th century, when Paul Ehrlich suggested that specific groups within a molecule are responsible for its biological activity [1,2]. The pharmacophore definition, as currently used, was developed over time, with many researchers actively participating in the process (for a detailed history of pharmacophores, please refer to Güner and Bowen [2]). However, Schueler provided the basis for our modern understanding of a pharmacophore [2,3], which is defined by the International Union of Pure and Applied Chemistry 
(IUPAC) as "the ensemble of steric and electronic features that is necessary to ensure the optimal supra-molecular interactions with a specific biological target structure and to trigger (or to block) its biological response" [4]. According to this definition, the interaction patterns of bioactive molecules with their targets are represented via a three-dimensional (3D) arrangement of abstract features that define interaction types rather than specific functional groups. These interaction types can, for example, include the formation of hydrogen bonds, charged interactions, metal interactions, or hydrophobic $(\mathrm{H})$ and aromatic (AR) contacts (Figure 1). Besides that, many pharmacophore modeling programs allow for the addition of steric constraints. These so-called exclusion volumes (XVols) mimic the geometry of the binding pocket and prevent the mapping of compounds that would be inactive in the experimental assessment due to clashes with the protein surface. In its entirety, a pharmacophore model represents one binding mode of ligands with a specific target, as exemplified on $17 \beta$-hydroxysteroid dehydrogenase (HSD) type 1 (Figure 1).
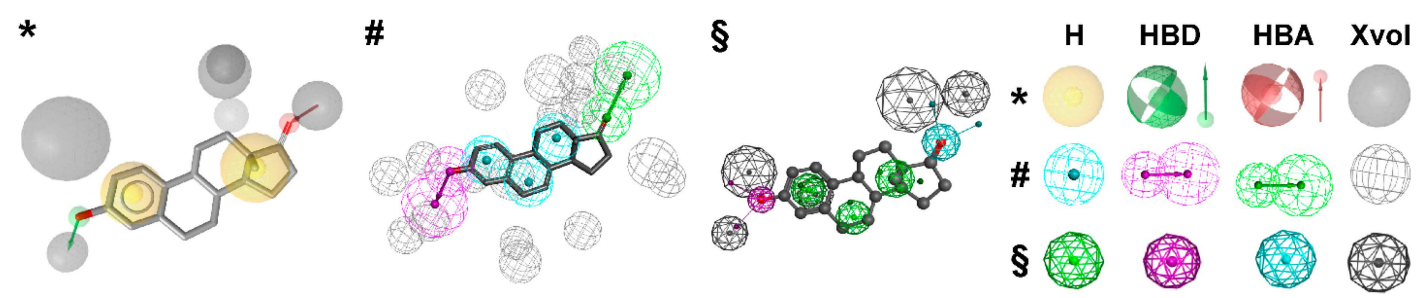

Figure 1. Pharmacophore models based on the estrogen equilin co-crystallized with $17 \beta$-hydroxysteroid dehydrogenase type 1 (PDB entry 1EQU [5]) and generated with LigandScout [6] (*), Discovery Studio [7] (\#), and Molecular Operating Environment (MOE) [8] (§). H, hydrophobic feature; HBD, hydrogen bond donor; HBA, hydrogen bond acceptor; XVols, exclusion volume.

Pharmacophore models can be generated using two different approaches (Figure 2) depending on the input data employed for model construction. In the structure-based approach, the interaction pattern of a molecule and its targets are directly extracted from experimentally determined ligand-target complexes (Figure 2A). An important source for these complexes, e.g., derived from NMR-spectroscopy or X-ray crystallography, represents the Protein Data Bank (PDB, www.pdb.org) [9]. To date (access date 2 November 2015), more than 113,000 macromolecular structures are stored in this online repository. However, not all of these structures were solved in a complex with a bound ligand, and in the case of induced fit, the binding of different ligands to an enzyme or receptor can lead to different interactions that are not covered by a single structure. To address this limitation, some pharmacophore modeling programs, e.g., Discovery Studio [7] and LigandScout [6], also provide tools to create pharmacophore models based exclusively on the topology of the binding site and in the absence of a ligand [10]. In Discovery Studio, for example, the binding site can be defined manually by selecting residues within the desired cavity or by applying implemented binding site identification tools. Once the binding site is defined, the program automatically calculates pharmacophore features based on the residues lining the active site. This initial ensemble of pharmacophore features can then be adapted to construct the final hypothesis [10]. In addition, structure-based pharmacophore models can also be generated with computationally derived ligand-target complexes. In the course of a docking run, known active compounds are fitted into the empty binding pocket of the target [11]. These docked binding poses can then directly be employed to extract the interaction patterns. For further refinement of the initial docking poses, molecular dynamics (MD) simulations can be conducted [12] prior to model generation.

In the course of ligand-based modeling, three-dimensional (3D) structures of two or more known active molecules are aligned and common pharmacophore features shared among these training set molecules are identified (Figure 2B). In a ligand-based approach, all of the common chemical features from the pharmacophore have to be presumed as essential, whereas in a structure-based approach, it can be considered whether a chemical feature of a molecule is directly involved in the ligand binding or not. 


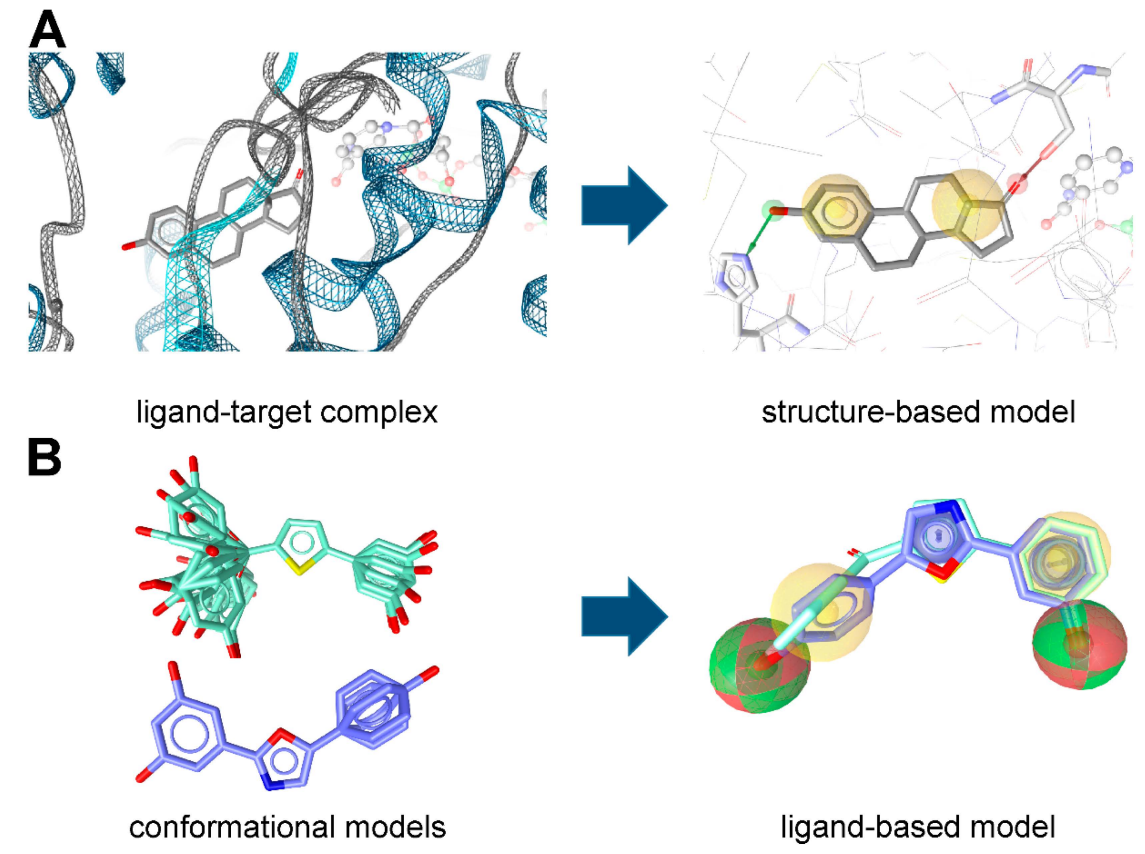

Figure 2. (A) Structure- and (B) ligand-based pharmacophore model generation with LigandScout. (A) Based on the complex of equilin bound to 17 $\beta$-HSD1 (PDB entry 1EQU [5]), an initial pharmacophore model is created automatically; (B) Conformational models of known 17 $\beta$-HSD1 ligands $[13,14]$ are used to align the compounds and extract pharmacophore features they share.

Usually, datasets containing known active and inactive molecules are employed to assess the quality of the developed models. These datasets need to be designed carefully, because they largely influence the quality of the model and, accordingly, the success of the study. Only active molecules should be included, for which the direct interaction has been experimentally proven [15,16], e.g., by receptor binding or enzyme activity assays on isolated or recombinant proteins. Cell-based assays should be avoided in this context, because many factors other than interaction with the target can influence the results: Active compounds may potentially exert their effect via other mechanisms than the intended one, whereas on the other hand, inactive compounds may actually interact with the target, but due to poor pharmacokinetic properties, this cannot be detected. In addition, appropriate activity cut-offs need to be defined to avoid the inclusion of compounds with a low binding affinity and high $\mathrm{EC}_{50} / \mathrm{IC}_{50}$ values (which may even be classified as "inactive"). Finally, the dataset should contain structurally diverse molecules [17] whenever possible. Preferably, experimentally confirmed inactive compounds should be included in the "inactives" dataset used for the theoretical validation $[17,18]$. Besides the original literature, several public compound repositories such as ChEMBL [19], Drugbank [20], or OpenPHACTS [21] can be explored for target-based activity data of compounds. In addition, several high-throughput screening (HTS) initiatives such as ToxCast [22], Tox21 [23], and PubChem Bioassay [24] provide a valuable resource for both active and inactive molecules. Whenever no or only a limited number of known inactive molecules are available, so-called decoys (compounds with unknown biological activity but assumed to be inactive) might be employed. These decoy-datasets need to be adapted for every target and should contain compounds with similar one-dimensional (1D) properties [25-27] but different topologies compared to the known active molecules. These properties can include the number of hydrogen bond donors (HBDs), the number of hydrogen bond acceptors (HBAs), the number of non-polar atoms [25], molecular weight, $\log$, and the number of rotatable bonds [27]. The Directory of Useful Decoys, Enhanced (DUD-E) [28] provides a free service (http:/ / dude.docking.org), where optimized decoys are generated based on the smiles codes of the uploaded active molecules. In general, a ratio of about 1:50 for the number of active molecules and decoys is recommended [28]. This should reflect the prospective screening 
database, where usually only a few active molecules are also distributed among a vast amount of inactive molecules (Figure 3).

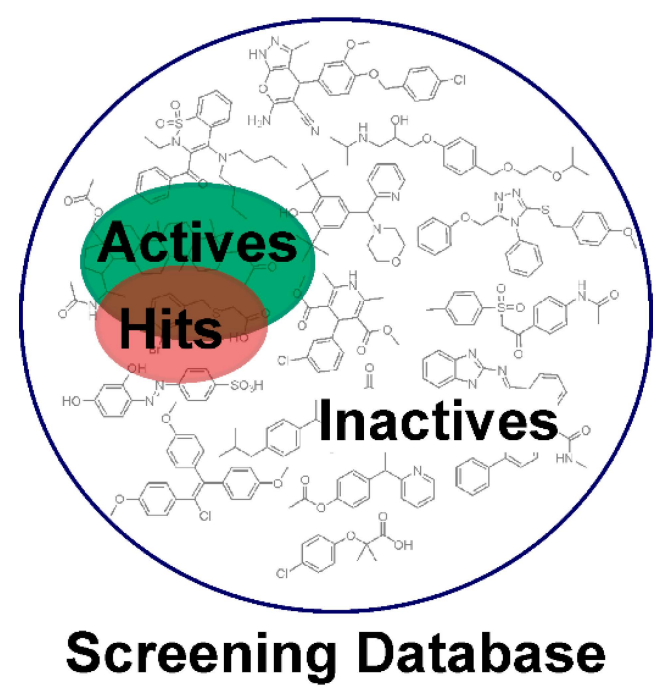

Figure 3. Enrichment of active molecules in the virtual hit list. Usually, the majority of compounds in a screening database are inactive molecules, while a small pool of bioactive molecules is contained. Pharmacophore-based virtual screening can help to enrich active molecules in the hit list compared to a random selection of test compounds.

The preliminary models generated with both approaches need further improvement in the majority of cases $[16,29]$ to facilitate the recovery of the active molecules and concomitantly exclude the inactive compounds in the dataset from the hit list. Basic model refinement steps include the deletion or addition of pharmacophore features and adaptations concerning the feature weight and size. Selected features can also be defined as optional and, therefore, can but do not have to be mapped by a molecule. In addition, a user-defined number of omitted features can be specified in many pharmacophore modeling programs. More sophisticated modifications comprise the modification of feature definitions, i.e., the functional groups covered by a pharmacophore feature.

The aim of pharmacophore-based virtual screening (VS) is to enrich active molecules in a screening database in the virtual hit list (Figure 3). Multiple quality metrics are available that help to evaluate the quality of the developed pharmacophore model, for example the enrichment factor [30] (the enrichment of active molecules compared to random selection), yield of actives (the percentage of active compounds in the virtual hit list), specificity (the ability to exclude inactive compounds) and sensitivity (the ability to identify active molecules), and the area under the curve of the Receiver Operating Characteristic plot (ROC-AUC) [31]. For detailed descriptions of commonly applied quality parameters we refer to earlier work $[15,16,26,32]$. The ultimate proof of a model's quality and value, i.e., whether it is indeed capable of proposing novel active molecules, can, however, only be determined in a prospective experiment, as will be explained in more detail below. A workflow summarizing the individual steps of pharmacophore model generation and application is depicted in Figure 4.

As outlined below, refined, high quality pharmacophore models can then be employed for multiple tasks. 


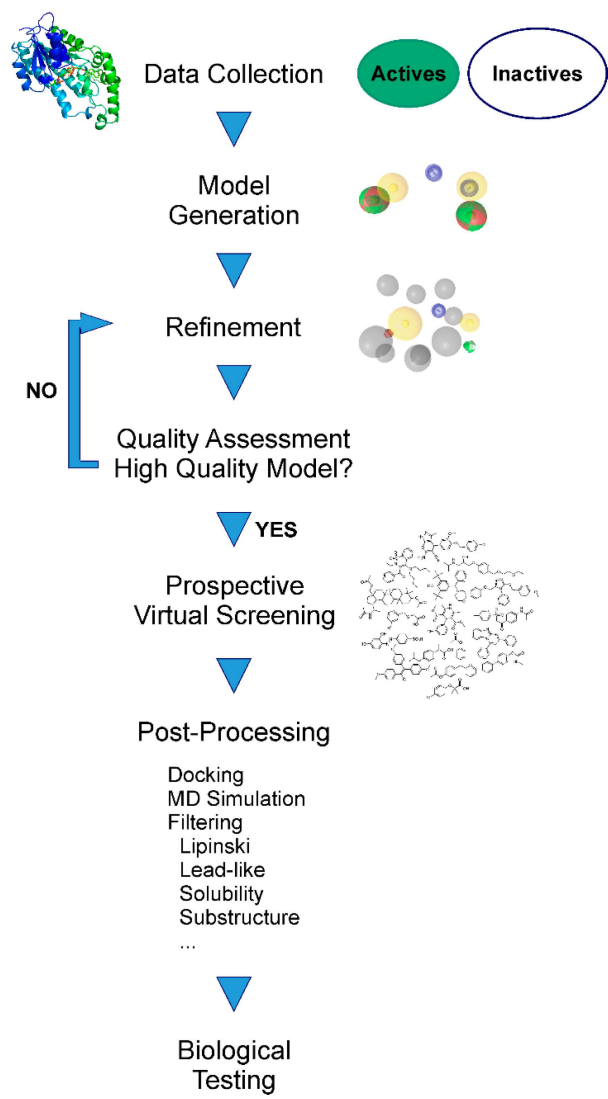

Figure 4. The different consecutive steps in pharmacophore model generation, refinement, and prospective application.

\section{Applications of Pharmacophore-Based VS}

In the course of a VS run, a pharmacophore model is screened against large chemical libraries, and molecules mapping the model are collected in a virtual hit list. These molecules fulfill the requirements of the model and therefore have a high likelihood to be active in the experimental testing. Accordingly, VS can be used to filter promising compounds out of large compound collections and enrich active molecules in chemical databases selected for experimental investigations. VS is considered a valuable support for classical HTS campaigns [33,34], because true positive hit rates are usually much higher than in those "random" testing strategies [35-37]. Reported hit rates from prospective pharmacophore-based virtual screening vary between individual studies, but are typically in the range of $5 \%$ to $40 \%$ (an excellent collection of prospective studies has been presented earlier [16]). On the other side, the hit rates of identifying active molecules upon random selection of test compounds are typically below $1 \%$ and have been described, for example, as $0.55 \%$ for glycogen synthase kinase-3 $\beta$ [36], $0.075 \%$ for peroxisome proliferator-activated receptor (PPAR) $\gamma[38]$, and $0.021 \%$ for protein tyrosine phosphatase-1B [37].

\subsection{Drug Discovery}

Pharmacophore-based VS is widely applied in different steps of the drug discovery process and facilitates the initial selection of compound classes as well as the optimization of compound properties as outlined below.

\subsubsection{Lead Identification}

The most common application of pharmacophore-based virtual screening concerns lead identification, the so-called cherry-picking approach. Virtual screening is often deployed in these 
projects to prioritize molecules for testing and minimizing the number of compounds to be investigated in biological screens. The ultimate aim is the identification of novel lead compounds for a specific disease-related target, which can be developed into drug candidates for the treatment of the intended disease, with numerous studies during the last years describing such applications [39-44]. For example, Ha et al. reported the discovery of novel ligands for the chemokine receptor CXCR2 by using a ligand-based pharmacophore modeling approach [45]. In the course of a pharmacophore-based virtual screening for novel histamine $\mathrm{H}_{3}$ receptor antagonists, Lepailleur et al. identified novel compounds additionally binding to the $5 \mathrm{HT}_{4}$ receptor [46]. Both activities were considered beneficial for the treatment of Alzheimer's disease and the authors were the first to report compounds with this dual mechanism of action [46].

\subsubsection{Structure-Activity Relationships}

As mentioned in the introduction, a pharmacophore model represents the putative binding mode of active molecules to their target. It therefore describes the crucial functionalities required for a compound's activity. A pharmacophore model is trained to discriminate between active and inactive molecules (in the best case even between members of the same chemical series), which makes it highly valuable for establishing structure-activity relationships (SARs). Differences in the experimentally observed biological activities of a set of compounds can be rationalized based on the presence/absence of chemical groups, represented by pharmacophore features, in the respective molecules. SARs can be established during model building, thereby elucidating the underlying mechanisms for the (absent) biological activity. For example, Ferreira et al. employed pharmacophore models to elucidate important features responsible for the interaction of compounds with the P-glycoprotein drug binding site [47]. Previous studies suggested a crucial role for a nitrogen atom in the modulators; however, active constituents from Euphorbia species isolated in-house did not contain such a moiety. The authors generated multiple refined pharmacophore models and evaluated them against a dataset of literature-derived modulators, the in-house collection, and inactive molecules. Their final model highlighted the important role of hydrophobic contacts and the presence of a HBA feature for P-glycoprotein modulators and showed that mapping of the most active compounds was also preserved when a further HBA/HBD feature was added [47]. In addition, pharmacophore models can be employed to reflect previously elucidated SARs for the identification of novel bioactive molecules. In 2002, Flohr et al. used the endogenous peptide urotensin II and synthetic analogues to experimentally identify interactions that are crucial for binding to the urotensin II receptor [48]. Based on the established SAR, pharmacophore models were built and employed to screen a chemical library containing small drug-like compounds. Subsequent experimental testing of the virtual hits led to the identification of six novel scaffold classes, which, importantly, contained non-peptic molecules [48].

\subsubsection{Scaffold Hopping}

A pharmacophore feature describes abstract chemical functionalities rather than specific functional groups. Additionally, pharmacophore models only demand local functional similarity of active compounds and virtual hits at 3D locations essential for biological activity. Therefore, there are no specifications concerning the actual two-dimensional (2D) structures of mapping compounds. Although the composition of a pharmacophore model is influenced by the 2D structure of the molecules employed for model generation and refinement, it still allows for mapping of structurally distinct hits. This makes pharmacophore modeling broadly applicable for the investigation of molecules originating from a diverse chemical space such as natural products and synthetic compounds. Importantly, it also allows for the identification of novel scaffolds that have not been associated with the target of interest before, a strategy that is called scaffold hopping. An earlier review extensively discussed pharmacophore modeling in the context of scaffold hopping [49]. A recent study employed pharmacophore modeling for the discovery of novel transient receptor potential vanilloid type 1 channel ligands [50]. Although the initial hits only weakly interacted with the target, they represent an 
interesting starting point for further chemical optimization. Such studies mostly emphasized novel chemical scaffolds and retrieved low similarity scores compared to the highly active compounds in the theoretical validation dataset [50].

Scaffold hopping is certainly relevant for the pharmaceutical industry that needs to explore compounds which are not yet covered by intellectual property issues. Of relevance for the general public, scaffold hopping facilitates the identification of chemicals with only limited available data. This is often the case for environmental pollutants and chemicals from consumer products that are often not drug-like by their nature.

\subsubsection{Selectivity Profiling}

For some projects, it may be of the utmost importance to identify compounds that selectively modulate the activity of one or more isoforms of an enzyme (family) to trigger the desired biological effect. For example, steroidal core structures are frequently found in endogenous and exogenous bioactive compounds; however, these compounds often lack selectivity. To identify selective compounds, specific chemical substitutions leading to additional hydrophobic or ionic interactions and hydrogen bonds have to be implemented. It has to be emphasized that these specific chemical modifications allow for distinguishing between the enzyme of interest and its related enzymes.

For example, 17 $\beta$-HSD1 inhibitors are promising drug candidates for the treatment of hormone-sensitive breast cancer as well as endometriosis because they block the activation of estrone to the highly potent endogenous estrogen receptor (ER) agonist estradiol [51-53]. On the other side, the converse reaction, (i.e., inactivation of estradiol) mediated via 17 $\beta$-HSD2, should not be blocked by these molecules. Ideally, bioassays of all relevant members within a given protein family would be employed to assess a compound's selectivity. Additionally, proteins sharing structural similarity in the domain that contains the ligand binding pocket rather than sequence similarity should be considered in the selectivity assessment of compounds [54,55]. Thus, a huge number of proteins need to be covered in this resource- and time-consuming approach. In a first step, parallel screening using a large collection of pharmacophores, covering the most relevant proteins, allows for an initial characterization of a compound's activity profile and facilitates the prioritization of the bioassays to be chosen for further biological analyses.

However, selectivity may not be limited to different isoforms. As exemplified by a study from Guasch et al., it can even address the biological effect exerted via the same target [56]. The authors focused on the exclusive discovery of novel PPAR $\gamma$ partial agonists. The retrieval of full agonists was avoided to prevent the side effects accompanying full receptor activation. For this purpose, a pharmacophore model for full agonists (called the anti-pharmacophore) was generated and used to remove all potential full agonists from the screening database. In the second step, a partial agonist pharmacophore model was applied to identify potential partial agonists in the compound library. After several additional filtering steps, eight compounds were finally subjected to biological testing and five of them could be confirmed as novel PPAR $\gamma$ ligands displaying partial agonistic effects [56].

\subsubsection{Combination with Other Techniques}

Pharmacophore models are also often used together with other methods to further increase the number of active molecules in the hit list via the application of a consensus approach. Commonly employed combinations comprise docking, shape-based modeling, and MD simulation.

In addition, a number of filters are available that help to limit the virtual hits to those with the desired properties and eliminate unwanted actions or molecules. Probably the most prominent filter represents the Lipinski's, describing properties that are shared by approved and orally administered drugs [57]. In particular, these comprise a number of $\leqslant 5 \mathrm{HBDs}, \leqslant 10 \mathrm{HBAs}$, a molecular weight of $\leqslant 500$, and $\operatorname{colog} P \leqslant 5$. Since all descriptors are either five or a multiple of five, Lipinski et al. referred to it as the "rule of five". Although the rule of five was initially developed to predict the oral bioavailability of molecules, it is also widely applied as a general drug-like filter. Veber et al. suggested two other 
criteria for the oral bioavailability of compounds: First, compounds should have a number of $\leqslant 10$ rotatable bonds and, second, either a polar surface area of $\leqslant 140 \AA^{2}$ or $\leqslant 12$ HBAs and HBDs [58].

In analogy to Lipinski's rule of five, Congreve et al. introduced the "rule of three" for the identification of promising hit compounds in fragment-based drug discovery [59]. Their analysis revealed that most of the small compounds that were successfully optimized to potent lead-like candidates had a molecular weight of $\leqslant 300$, a number of HBDs $\leqslant 3$, a number of HBAs $\leqslant 3$, and a $\operatorname{cLog} \mathrm{P} \leqslant 3$ [59].

More recently, a substructure filter was developed to identify highly problematic compounds that notoriously produce false positive assay read-outs [60]. Baell and Holloway analyzed high-throughput testing results and observed that a group of molecules were prone to unspecifically interfere with some experimental test systems. The subsequently developed substructure filter can help to detect these pan-assay-interference compounds (PAINS) [60] prior to spending time and resources in investigating and optimizing such molecules [61].

Multiple of these methods and filters can be included as well. As an example, Noha et al. employed a variety of computational techniques in a sequential manner to identify novel inhibitors of microsomal prostaglandin $E_{2}$ synthase-1 [62]. The workflow included multiple prefilters, among them also the Lipinski filter, a pharmacophore-based virtual screening procedure, and molecular docking. Out of the 17 molecules finally selected for testing, two showed good activity in the experimental assay, and two further had moderate effects. Temml et al. used a combination of pharmacophore- and shape-based virtual screening to identify novel liver $X$ receptor agonists [44]. In their study mentioned above [56], Guasch et al. not only applied pharmacophore models, but also a multistep protocol comprised of electrostatic and shape similarity and molecular docking to identify novel PPAR $\gamma$ partial agonists.

\subsection{The Short-Chain Dehydrogenase/Reductase Superfamily}

The short-chain dehydrogenase/reductase (SDR) enzyme family are nicotinamide adenine dinucleotide NAD (phosphate (P))-dependent enzymes sharing a common core structure of up to seven parallel stranded $\beta$-sheets flanked by three to four $\alpha$-helices on each side, the so-called Rossmann fold, for $\mathrm{NAD}(\mathrm{P})$ binding and a catalytic center characterized by a Tyr-(Xaa) ${ }_{3}$-Lys motif. This motif is often found in combination with a conserved serine residue that stabilizes the orientation of the bound substrate (Figure 5) [63]. SDRs typically share a low sequence identity between $20 \%-30 \%$, but with considerable structural similarity in the core domain.

The SDR family contains HSDs that play key roles in adrenal and gonadal steroidogenesis as well as in the metabolism of steroids in peripheral tissues [64]. Some of these HSDs are considered as promising therapeutic targets for the treatment of estrogen- and androgen-dependent diseases such as osteoporosis, endometriosis, and breast and prostate cancer, and other enzymes gained interest regarding the treatment of corticosteroid-related diseases such as diabetes, visceral obesity and dyslipidemia, atherosclerosis, wound healing, glaucoma, neurodegenerative disease, and cognitive impairment [53,65-67].

The development of specific SDR inhibitors needs to take into account the structural similarity of the various SDR enzymes in order to exclude the inhibition of members causing adverse effects, so-called off-targets. Suitable enzyme activity assays are fundamental for selectivity testing of potential inhibitors. Koch et al. proposed that structural similarity rather than primary sequence similarity should be chosen as the criterion for whether a certain chemical affects the activity of a related enzyme [54]. Therefore, the closest structurally related enzymes should be included for selectivity testing - using pharmacophore models and cell-based assays. Another application of the modeling approaches is the identification of toxic xenobiotics including industrial and environmentally relevant chemicals [68-70]. The role of several SDRs in xenobiotics metabolism and in steroid synthesis and metabolism makes them prone as targets for endocrine disruption [71-76]. 


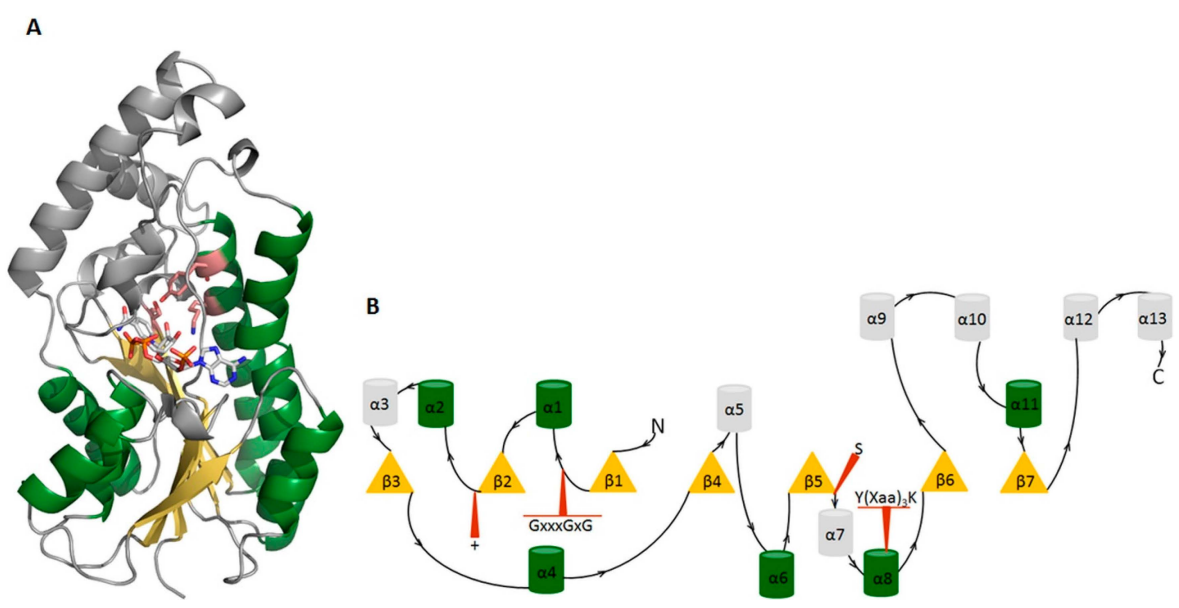

Figure 5. The general structure of SDR enzymes exemplified on 17 $\beta$-HSD1 (PDB entry 1EQU [5]). (A) The Rossmann fold consists of parallel stranded $\beta$-sheets (yellow), which are flanked by $\alpha$-helices on both sides (green). This structural domain forms the binding site of the co-factor NADP+. The residues Tyr155 and Lys159 of the Tyr-(Xaa)3-Lys motif as well as the conserved Ser142 are highlighted in rose; (B) 2D depiction of 17 $\beta$-HSD1 (PDB entry 1EQU). Yellow triangles display $\beta$-sheets and barrel symbols $\alpha$-helices. Apart from the Rossmann fold, structurally conserved regions are highlighted in red. The conserved glycine-rich motif GxxxGxG is important for cofactor binding and the + indicates a positive charged residue crucial for cofactor (NADP+) stabilization.

\section{Examples from the SDR Family}

\subsection{1ß-Hydroxysteroid Dehydrogenase Type 1}

The two isoenzymes of $11 \beta$-HSD catalyze the interconversion of the biologically inactive cortisone and the active cortisol (Figure 6). The 11 $\beta$-HSD1 is ubiquitously expressed and mediates the regeneration of active glucocorticoids $[77,78]$, whereas $11 \beta$-HSD2 catalyzes the inactivation of glucocorticoids mainly in the kidney, colon and placenta. There is evidence for beneficial effects of $11 \beta-H S D 1$ inhibition in the metabolic syndrome [79-87], atherosclerosis [88-91], osteoporosis [66,92], glaucoma [93-95], cognitive functions [96-100], skin aging [101], and wound healing [102,103]. Thus, inhibition of $11 \beta-H S D 1$ has substantial therapeutic potential for glucocorticoid-related diseases. Numerous $11 \beta-H S D 1$ inhibitors have already been identified and some have reached the clinical phase, but to date still no 11 -HSD1 inhibitor is on the market [104]. Although structural variety is prevalent among the $11 \beta-H S D 1$ inhibitors, the crystal structures are rather similar [105]. Nevertheless, the observed differences are useful in selecting a structure for further in silico evaluations. To date, 27 human, four mouse, and three guinea pig $11 \beta-H S D 1$ crystal structures are accessible through the PDB; however, there is currently no 3D structure of human $11 \beta-H S D 1$ in -complex with a substrate available. In addition, structural information about $11 \beta-H S D 2$ is entirely missing.
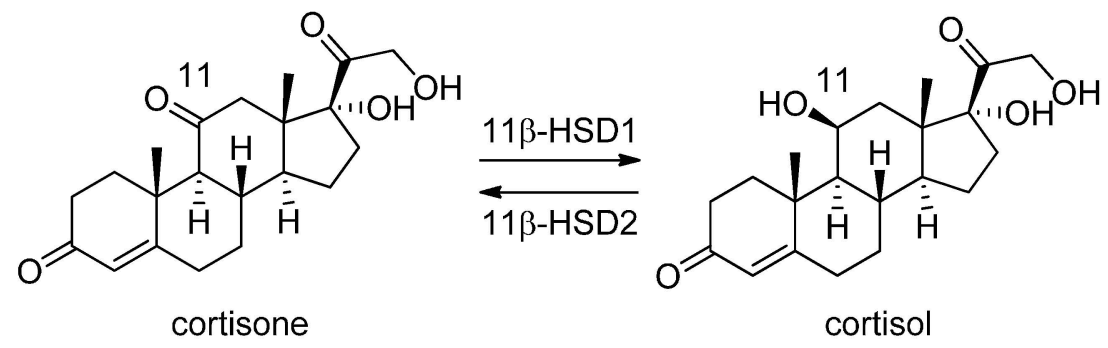

Figure 6. Interconversion of cortisone and cortisol catalyzed by the $11 \beta-H S D$ enzymes. 
Schuster and Maurer et al. [106] were the first to introduce pharmacophore models for the identification of novel classes of $11 \beta$-HSD1 inhibitors. As there was no X-ray crystal structure of $11 \beta$-HSD1 available at the beginning of their study, they employed two ligand-based pharmacophore models as VS tools. Depending on the $11 \beta$-HSD activity of the training compounds used for the model generation, a model for $11 \beta$-HSD1-selective (Figure 7A) and one for nonselective 11 $\beta$-HSD inhibitors (Figure 7B), preferably targeting $11 \beta$-HSD2, were developed. These models identified compounds resembling the structure of the known unselective 11ß-HSD inhibitor glycyrrhetinic acid (GA), steroid-like compounds, and novel structural classes. A comparison of the training set compounds used for the generation of the 11 $\beta$-HSD1-selective and the $11 \beta$-HSD-nonselective pharmacophore models with the compounds from the VS showed similar inhibition profiles towards 11ß-HSD1 and 11ß-HSD2.

A

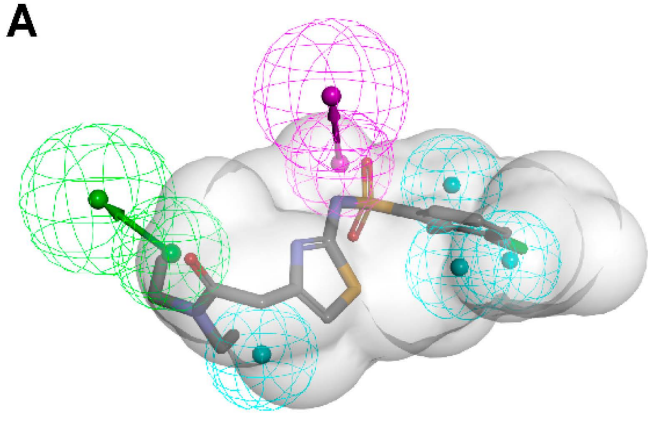

B

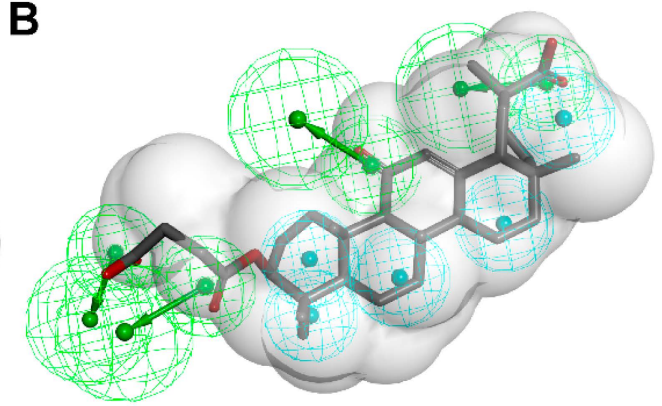

Figure 7. The selective (A) and nonselective (B) 11 $\beta$-HSD1 pharmacophore models reported in the study by Schuster and Maurer [106]. The training compounds CAS 376638-65-2 (A) and carbenoxolone

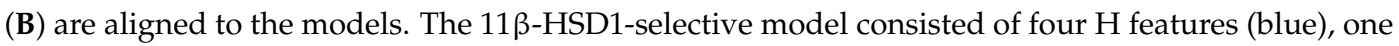
HBA (green) and one HBD (magenta) feature and a shape restriction. The nonselective 11 $\beta$-HSD model contained five $\mathrm{H}$, four HBA features and also a shape restriction.

Testing the inhibitory potential of their VS hits, Schuster and Maurer et al. determined biological

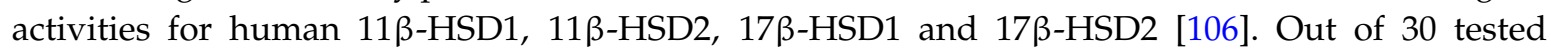
compounds, seven inhibited $11 \beta$-HSD1 activity by more than $70 \%$ at $10 \mu \mathrm{M}$ and only three showed reasonable selectivity over the other tested enzymes.

The potential of the selective 11ß-HSD1 ligand-based pharmacophore model obtained by Schuster and Maurer et al. [106] was further evaluated by Hofer et al. [107]. VS and subsequent lead optimization by classical bioisosteric studies revealed a class of selective 11 $\beta$-HSD1 inhibitors bearing an arylsulfonylpiperazine scaffold. Docking studies, performed to rationalize the biological data, showed good alignment of all active compounds with the co-crystallized ligand, belonging to the same chemical scaffold. This structure-based approach further validated the ligand-based pharmacophore model.

Rollinger $e t$ al. used the same pharmacophore model as a query for the screening of a database consisting of constituents from medicinal plants, in order to identify natural compounds selectively inhibiting 11ß-HSD1 [108]. The chemical class of triterpenoids displayed one of the dominating chemical scaffolds in the virtual hit list. Earlier investigations led to the assumption that extracts from the anti-diabetic medical plant loquat (Eriobotrya japonica) dose-dependently and preferentially inhibit 11 $\beta$-HSD1 over 11 $\beta$-HSD2 [109]. Therefore, the virtual screening hit corosolic acid, a known constituent of E. japonica, was tested and identified as potent inhibitor of human 11ß-HSD1 with an $\mathrm{IC}_{50}$ of $810 \mathrm{nM}$ [108]. Subsequent bioassay-guided phytochemical analyses revealed further secondary metabolites from the triterpenoid ursane type as $11 \beta$-HSD1 inhibitors with $\mathrm{IC}_{50}$ in the micromolar range. Importantly, a mixture of the constituents with moderate inhibitory activities displayed an additive effect. This is a common observation in phytotherapy, where a mixture of constituents is often responsible for the therapeutic effect. Docking studies for binding mode prediction suggested a flipped binding mode, where these triterpenoids would not interact with the catalytic amino acids but 
with Thr124 and Tyr177 (Figure 8). Based on the most active compounds, a pharmacophore model was generated that enriched active molecules on the top of the hit list and successfully reflected the substructures important for binding. Additionally, this study demonstrates a further application in the drug discovery process—-finding inhibitors from natural origins.

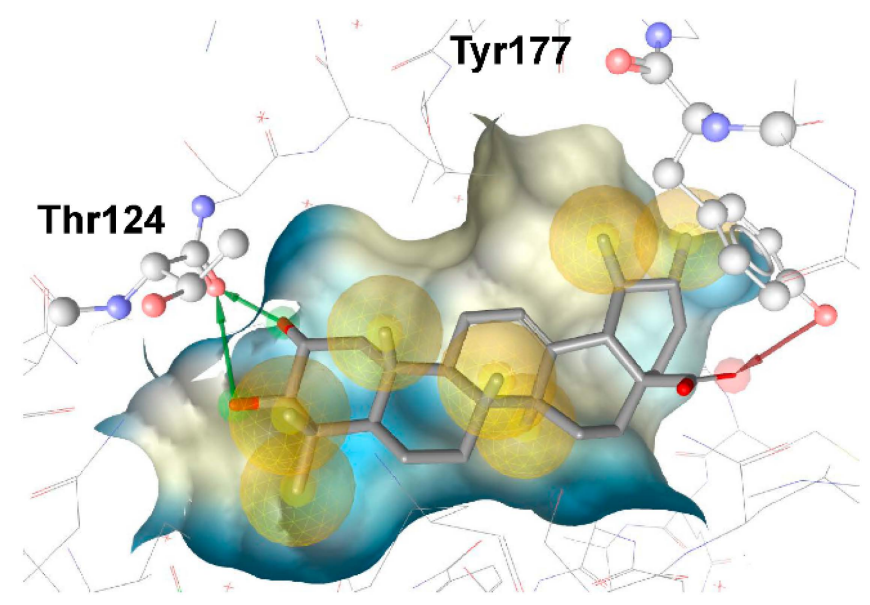

Figure 8. The docking pose of the potent inhibitor corosolic acid in the binding pocket of 11ß-HSD1 (PDB entry 2BEL [110]) suggests interactions with Thr124 and Tyr177.

Considering the ongoing search for novel $11 \beta$-HSD1 inhibitors, high predictivity and performance of pharmacophores are essential. Thus, to maintain high quality standards, pharmacophore models have to be continuously re-evaluated and improved. Vuorinen et al. [29] performed a refinement study of the 11ß-HSD pharmacophore models previously described by Schuster and Maurer et al. [106] and Kratschmar et al. [78]. In a first step, the selective 11 $\beta$-HSD1 model was refined by exchanging a chemical feature and removing shape restriction using literature data. Whereas the unrefined model was only able to recognize two out of 14 test compounds, the refined model found 13. Subsequent prospective VS and biological testing revealed better performance of the refined model. However, although the refinement improved the sensitivity of the model and more active compounds were found, it decreased specificity and also more inactive compounds fitted into the model. Adding a shape restriction, following newly identified selective 11ß-HSD1 inhibitors, increased specificity, whereas the sensitivity remained the same. For additional testing of the model quality on a different dataset, literature-based validation was performed with structurally diverse compounds, which had not been used in the model development. Specificity was increased, whereas sensitivity decreased. This illustrates that improvement of model quality is accompanied by balancing the specificity and sensitivity of a model. Refinement of the $11 \beta-H S D 2$-selective model was equally conducted. Since there is no 3D structure of $11 \beta$-HSD2 available and only a few selective, mainly triterpenoid scaffold-based $11 \beta-H S D 2$ inhibitors are known, the $11 \beta-H S D 2$ model data are biased. They were, however, able to improve $11 \beta-H S D 2$ model quality, and novel active scaffolds selectively inhibiting both $11 \beta-H S D 1$ (Figure 9A) and 11 $\beta$-HSD2 (Figure 9B) were discovered [29].

Using the refined 11 $\beta-H S D 1$ model, Vuorinen et al. applied a VS to filter a database consisting of constituents from medicinal plants to identify potential 11 $\beta$-HSD1 inhibitors focusing on triterpenoids present in Pistacia lentiscus (P. lentiscus), so-called mastic gum that is used in traditional Greek medicine for the treatment of diabetes [111]. The VS hit list contained eight hits of $P$. lentiscus constituents. The two main constituents of mastic gum, masticadienonic acid and isomasticadienonic acid, were chosen for further biological evaluation. Both compounds were shown to selectively inhibit 11ß-HSD1 over $11 \beta$-HSD2 with $\mathrm{IC}_{50}$ values of $2.51 \mu \mathrm{M}$ for masticadienonic acid and $1.94 \mu \mathrm{M}$ for isomasticadienonic acid, respectively. Examination of the whole resin's activity revealed half the $\mathrm{IC}_{50}$ value of the single molecules, suggesting an additive inhibitory effect. Thus, the hypothesis of $11 \beta$-HSD1 involvement in the antidiabetic activity of mastic gum was supported. Analyzing the binding orientation of the 
two substances by docking revealed interactions comparable to that of the co-crystallized ligand carbenoxolone, suggesting a competitive binding mode. Thus, the refined pharmacophore model has proven its ability to identify novel $11 \beta-H S D 1$ inhibitors from natural sources.

A

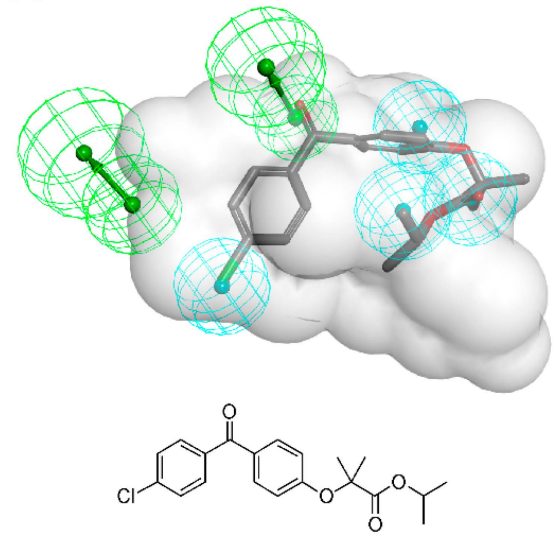

B

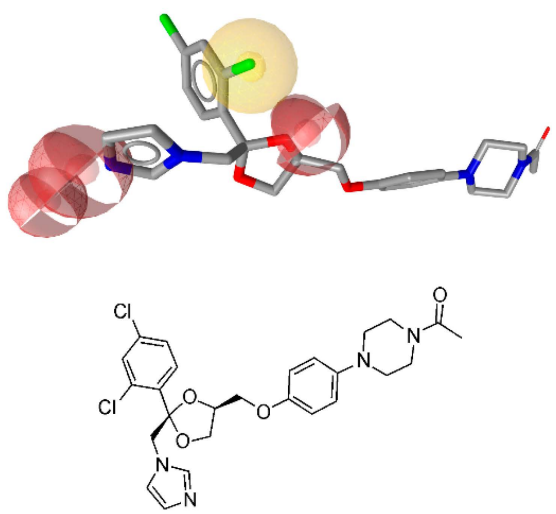

Figure 9. Both the refined 11 -HSD1 (A) and 11ß-HSD2 (B) model identified novel scaffolds [29]. The inhibitor fenofibrate maps the $11 \beta$-HSD1 model (A) and ketoconazole matches the 11 $\beta$-HSD2 model (B). Both models were screened with one omitted feature. The $2 \mathrm{D}$ structures of the novel inhibitors are depicted underneath the alignments.

Yang et al. performed a study using different $11 \beta$-HSD1 crystal structures in order to identify synthetic 11ß-HSD1 inhibitors [112]. They applied a combined approach of molecular docking and ligand-based pharmacophore modeling. For virtual docking calculations the crystal structure 1XU9 [113] and the program DOCK4.0 [114] were used to screen a commercial compound database. The 3000 compounds with the highest docking score were selected for a second docking run using Glide [115]. Additionally, a ligand-based pharmacophore model for selective 11 $\beta$-HSD1 inhibitors was constructed using Catalyst 4.10 [116], which was used for screening the 3000 compounds with the Best Flexible Search mode. Compounds with high docking and good fit score were further evaluated by filtering for drug likeness and finally selected for biological testing on human and mouse $11 \beta$-HSD1. Importantly, other studies showed significant species-specific variability in the potency of various $11 \beta$-HSD1 inhibitors, indicating significant differences in the 3D organization of the hydrophobic substrate-binding pocket of human and mouse 11 $\beta-H S D 1[117,118]$. Due to this issue, the tested compounds showed different inhibition profiles for the mouse and human enzyme. Eleven out of 121 tested compounds inhibited the human $11 \beta-H S D 1$ with IC $_{50}$ values of $0.26-14.6 \mu \mathrm{M}$, whereas six molecules inhibited the mouse $11 \beta-H S D 1$ with $\mathrm{IC}_{50}$ values of $0.48-12.49 \mu \mathrm{M}$. Two substances displayed overlapping hits with $\mathrm{IC}_{50}$ for the human $11 \beta-\mathrm{HSD} 1$ of $0.69 \mu \mathrm{M}$ and $3.57 \mu \mathrm{M}$ and for the mouse isoenzyme of $0.48 \mu \mathrm{M}$ and $2.09 \mu \mathrm{M}$, respectively. In order to test the selectivity over $11 \beta-H S D 2$ for subsequent animal studies, only compounds inhibiting mouse 11 $\beta$-HSD1

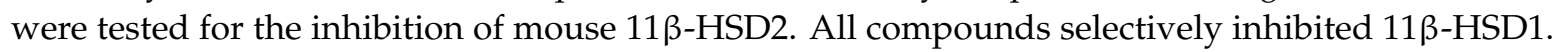
Nevertheless, selectivity assessment needs to include human 11 $\beta$-HSD2 and, ideally, other SDRs. Cross-species activity would be the optimal situation for preclinical evaluation in the development of novel drug candidates.

A consecutive in silico study of Yang et al. includes virtual screening with 11ß-HSD1 structure-based pharmacophore models and subsequent docking for hit selection [119]. Compounds chosen in the docking process were able to form hydrogen bonds with the amino acids Tyr183 and Ser170 from the catalytic triade. Nine out of 56 enzymatically tested compounds exhibited dose-dependent and selective inhibition of human 11ß-HSD1 with $\mathrm{IC}_{50}$ values between $0.85-7.98 \mu \mathrm{M}$ and six substances inhibited the mouse $11 \beta-\mathrm{HSD} 1$ with $\mathrm{IC}_{50}$ values between $0.44 \mu \mathrm{M}$ and $8.48 \mu \mathrm{M}$. 
Four substances inhibited both isoenzymes with similar $\mathrm{IC}_{50}$ values. In contrast, during their first $11 \beta-H S D 1$ in silico study, Yang et al. identified 11 out of 121 tested compounds from the same database as actives against $11 \beta-\mathrm{HSD} 1$, with $\mathrm{IC}_{50}$ values between $0.26-14.6 \mu \mathrm{M}$ [113]. Four of the identified $11 \beta$-HSD1 inhibitors incorporate an arylsulfamido scaffold, an already reported scaffold to inhibit $11 \beta$-HSD1 [118]. Besides, three new scaffolds were identified as displayed in Figure 10.<smiles>Cc1cccc(OCC(=O)N/N=C/c2c(C)cc(O)cc2O)c1</smiles><smiles>NS(=O)(=O)c1cc(C(=O)O)c(NCc2ccco2)cc1Cl</smiles><smiles>Cc1ccc(CSc2nnc(N3C(=O)C(O)=C(C(=O)c4cc5ccccc5o4)C3c3ccccc3F)s2)cc1</smiles>

Figure 10. The three new identified scaffolds by Yang et al. [119].

Table 1 summarizes the pharmacophore-based virtual screening studies and illustrates the scaffold-hopping of the different $11 \beta$-HSD1 inhibitors.

\subsubsection{7 $\beta$-Hydroxysteroid Dehydrogenase Type 1}

To date, 14 different human $17 \beta$-hydroxysteroid dehydrogenase (17 $\beta$-HSD) enzymes have been reported, all of which except the aldo-keto reductase (AKR) member 17 $\beta$-HSD5 (AKR1C3) belong to the SDR family [120]. The $17 \beta$-HSDs essentially regulate the local metabolism and activity of estrogens and androgens (Figure 11).

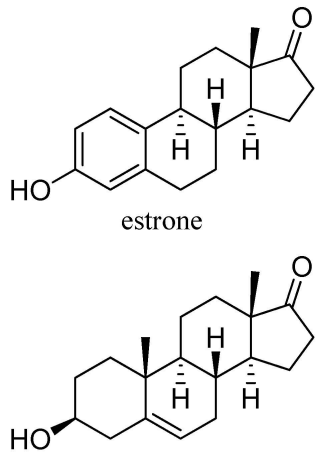

dehydroepiadrosterone

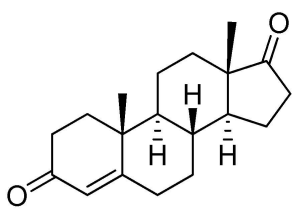

4-androstene-3,17-dione

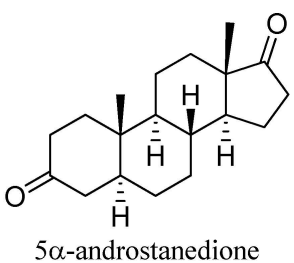

$\underset{17 \beta-H S D 2}{\stackrel{17 \beta-H S D 1}{\rightleftarrows}}$<smiles>CC12CCC3c4ccc(O)cc4CCC3C1CCC2O</smiles>

$17 \beta-H S D 1$ $17 \beta$-HSD5

$17 \beta-H S D 2$

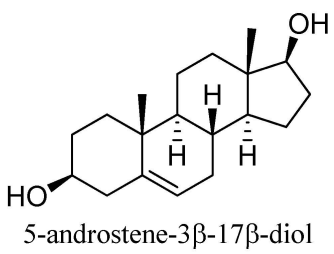

17ß-HSD3 17ß-HSD5

17ß-HSD2<smiles></smiles><smiles>[PbH3]</smiles>

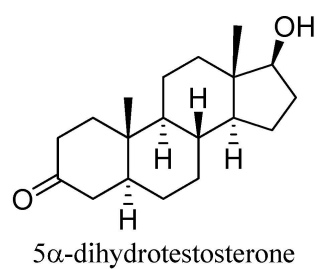

Figure 11. 17 $\beta$-HSDs involved in sex steroid metabolism. 
Table 1. 11 $\beta$-HSD1 pharmacophore-based virtual screening studies summarized.

\begin{tabular}{|c|c|c|c|c|c|c|c|c|c|}
\hline \multirow[b]{2}{*}{ Reference Study Aim } & \multirow[b]{2}{*}{$\begin{array}{l}\text { Pharmacophore } \\
\text { Model }\end{array}$} & \multirow[b]{2}{*}{$\begin{array}{l}\text { Database Used } \\
\text { for VS }\end{array}$} & \multicolumn{4}{|c|}{ Hits } & \multicolumn{3}{|c|}{ Biological Testing } \\
\hline & & & Most Active Hit & $\begin{array}{l}\text { Number of } \\
\text { Virtual Hits }\end{array}$ & $\begin{array}{l}\text { Tested in } \\
\text { Vitro }\end{array}$ & Actives & Assay & $\mathrm{IC}_{50}$ & Selectivity \\
\hline \multirow{3}{*}{$\begin{array}{l}\text { Schuster and } \\
\text { Maurer et al. [106] } \\
11 \beta \text {-HSD1 inhibitors }\end{array}$} & $\begin{array}{l}\text { Ligand-based } \\
\text { using Catalyst }\end{array}$ & \multirow{3}{*}{$\begin{array}{l}\text { Asinex Gold and } \\
\text { Platinum, Bionet } \\
\text { 2003, ChemBridge } \\
\text { DBS, Clab and } \\
\text { IDC, Enamine 03, } \\
\text { Interbioscreen } 03 \\
\text { nat and syn, } \\
\text { Maybridge } 2003 \text {, } \\
\text { NCI, Specs } 0903\end{array}$} & & \multirow[t]{2}{*}{$16 / 20304$} & \multirow[t]{2}{*}{15} & \multirow[t]{2}{*}{2} & \multirow[t]{2}{*}{ Lysate } & \multirow[t]{2}{*}{2.03 and $7.59 \mu \mathrm{M}$} & \multirow{2}{*}{$\begin{array}{l}\text { Against } \\
11 \beta \text {-HSD2, } \\
17 \beta-H S D 1, \text { and } \\
17 \beta-H S D 2\end{array}$} \\
\hline & $\begin{array}{l}11 \beta \text {-HSD1 selective } \\
(4 \mathrm{H}, 1 \mathrm{HBA}, 1 \mathrm{HBD}, \\
\text { and shape restriction) }\end{array}$ & & & & & & & & \\
\hline & $\begin{array}{l}11 \beta \text {-HSD unselective } \\
(5 \mathrm{H}, 4 \mathrm{HBA} \text { and } \\
\text { shape restriction) }\end{array}$ & & & $107 / 1776579$ & 15 & 5 & Lysate & $\begin{array}{l}11 \beta \text {-HSD1 } 0.144-2.81 \mu \mathrm{M} \\
11 \beta \text {-HSD2 } 0.06-3.95 \mu \mathrm{M}\end{array}$ & $\begin{array}{l}\text { Most of them } \\
\text { against 17 } \beta \text {-HSD1 } \\
\text { and 17 } \beta \text {-HSD2 }\end{array}$ \\
\hline $\begin{array}{l}\text { Hofer et al. [107] } \\
\text { Lead optimization }\end{array}$ & $\begin{array}{l}11 \beta \text {-HSD1 selective } \\
\text { from Schuster and } \\
\text { Maurer et al. [106] }\end{array}$ & In-house database & & - & - & - & Lysate & $0.7 \mu \mathrm{M}$ & $\begin{array}{l}\text { Against } \\
11 \beta-H S D 2\end{array}$ \\
\hline $\begin{array}{l}\text { Rollinger et al. [108] } \\
\text { Natural compounds } \\
\text { inhibiting } 11 \beta-H S D 1\end{array}$ & $\begin{array}{l}11 \beta \text {-HSD1 selective } \\
\text { from Schuster and } \\
\text { Maurer et al. [106] }\end{array}$ & $\begin{array}{l}\text { DIOS (Natural } \\
\text { products in-house } \\
\text { database) }\end{array}$ & & 172 & 1 & 1 & Lysate & $0.81 \mu \mathrm{M}$ & $\begin{array}{l}\text { Against } \\
\text { 11 } \beta \text {-HSD2 }\end{array}$ \\
\hline \multirow{4}{*}{$\begin{array}{l}\text { Vuorinen et al. [29] } \\
\text { Refinement study }\end{array}$} & $\begin{array}{l}\text { Refined models from } \\
\text { Schuster and } \\
\text { Maurer et al. [106] } \\
\text { Using Discovery } \\
\text { Studio }\end{array}$ & $\begin{array}{l}\text { In-house } \\
\text { database, DIOS }\end{array}$ & & 463 & 9 & 3 & \multirow{4}{*}{ Lysate } & \multirow{2}{*}{$\begin{array}{l}\text { Considered as active } \\
\text { if remaining enzyme } \\
\text { activity } \leqslant 55 \% \text { at test } \\
\text { substance concentration } \\
\text { of } 20 \mu \mathrm{M} \text { or } \leqslant 65 \% \text { at test } \\
\text { substance concentration } \\
\text { of } 10 \mu \mathrm{M} 5 \%-40 \%\end{array}$} & \multirow[t]{2}{*}{$\begin{array}{l}\text { Two preferentially } \\
\text { inhibited } \\
11 \beta \text {-HSD2, one } \\
\text { was unselective }\end{array}$} \\
\hline & $11 \beta$-HSD1 selective & & fenofibrate & & & & & & \\
\hline & $11 \beta$-HSD2 selective & $\begin{array}{l}\text { In-house } \\
\text { database, Specs, } \\
\text { Maybridge }\end{array}$ & $\begin{array}{l}\mathbb{L N}_{N} \\
\text { ketoconazole }\end{array}$ & 444 & 25 & 2 & & $\begin{array}{l}11 \%-61 \% \text { Enzyme rest } \\
\text { activity }\end{array}$ & $\begin{array}{l}\text { One preferentially } \\
\text { inhibited } \\
11 \beta-H S D 1 \text { and } \\
\text { one was } \\
\text { unselective }\end{array}$ \\
\hline & $11 \beta$-HSD unselective & $\begin{array}{l}\text { EDC, In-house } \\
\text { database }\end{array}$ & & 38 & 4 & & & $\begin{array}{l}36 \%-49 \% \text { Enzyme rest } \\
\text { activity }\end{array}$ & $\begin{array}{l}\text { Two preferentially } \\
\text { inhibited } \\
\text { 11 } \beta \text {-HSD1 one } \\
\text { preferentially } \\
\text { inhibited } \\
\text { 11 } \beta \text {-HSD2 }\end{array}$ \\
\hline
\end{tabular}


Table 1. Cont.

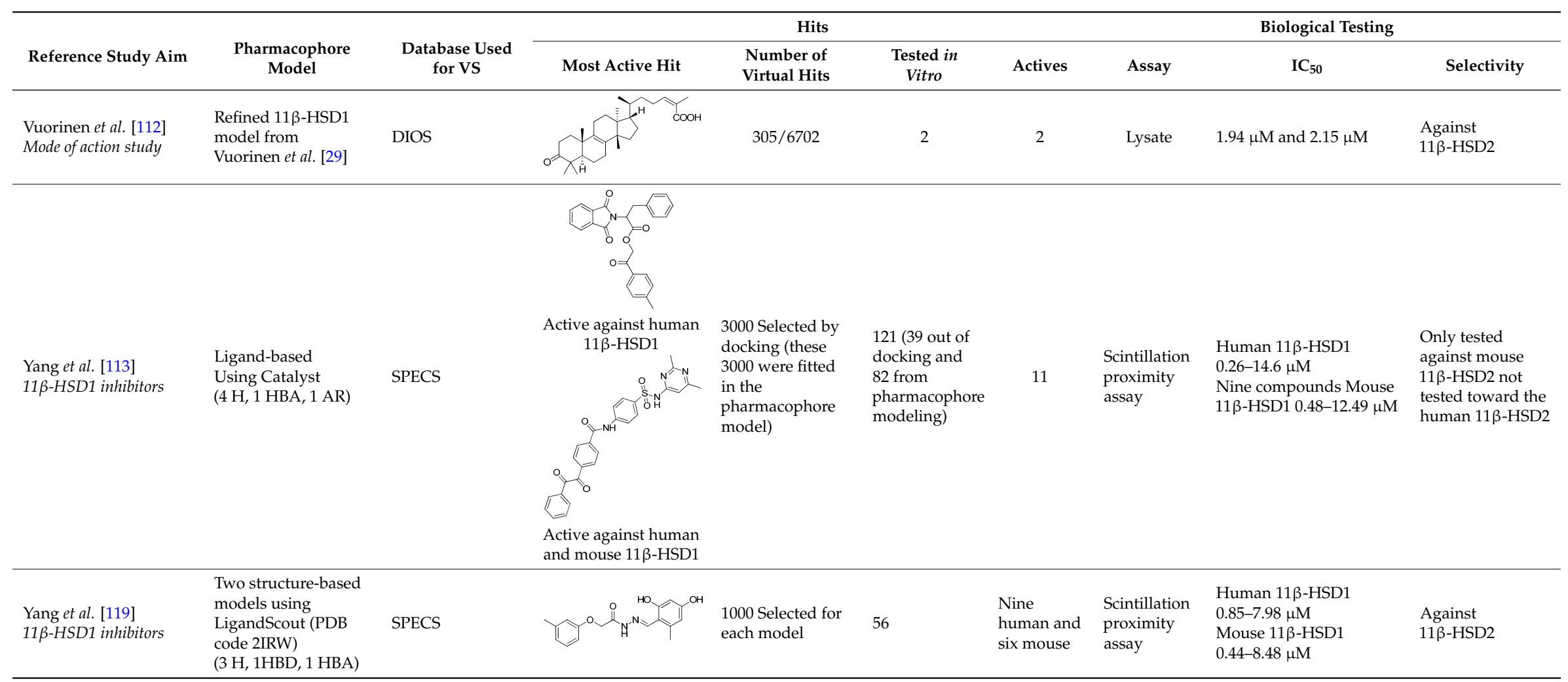


The enzyme 17 $\beta$-HSD1 catalyzes the NADP $(\mathrm{H})$-dependent reduction of the weak estrogen estrone to the potent estradiol and to a minor extent of dehydroepiandrosterone (DHEA) to 5 -androstene-3 $\beta, 17 \beta$-diol [121]. 17 $\beta$-HSD1 is predominantly expressed in the human placenta, ovaries, and mammary gland, and is of major importance for the peripheral and gonadal estradiol synthesis [122]. Several studies provide evidence for the association of $17 \beta-H S D 1$ with breast cancer [123-125], endometriosis [52,126], endometrial cancer [127] and uterine leiomyoma [128].

Despite the recently increasing numbers of reported 17 $\beta$-HSD1 inhibitors, still no compound reached clinical trials. To date, more than 20 crystal structures have been published. The binding pocket of 17 $\beta$-HSD1 is an elongated hydrophobic tunnel, with key roles for Leu149, Val225, Phe226, and Phe259, and polar areas at each end formed by His221 and Glu282 on one side and the catalytically essential residues Ser142 and Tyr155 on the other side. The active site is limited by a flexible loop (amino acids 188-201), which is not well resolved in the crystal structures (Figure 12) [13].

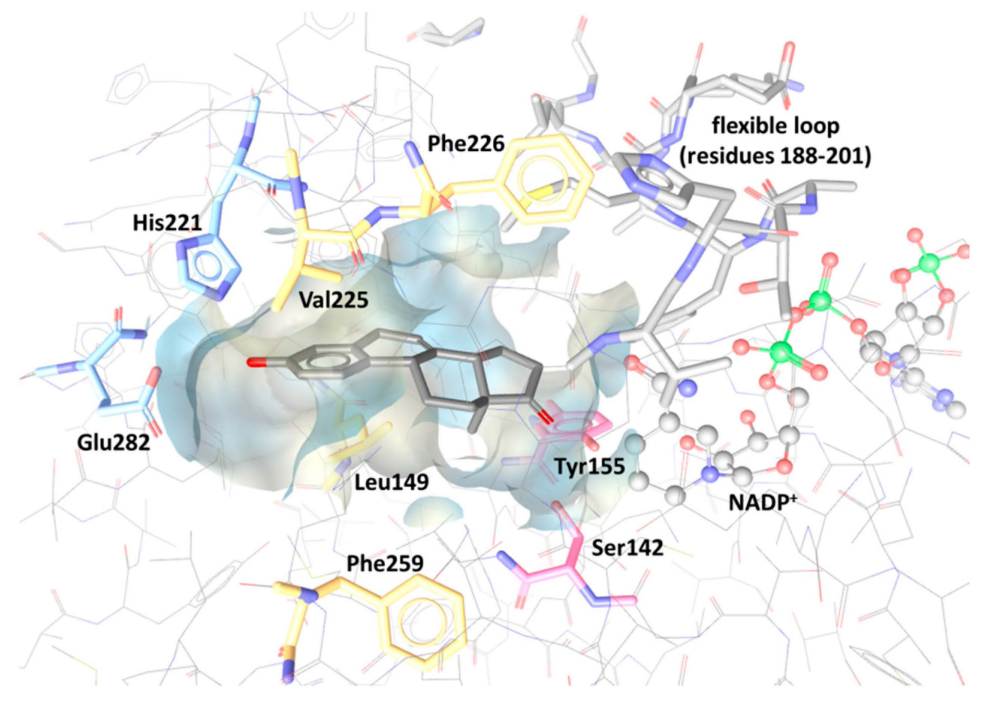

Figure 12. Shape binding site of $17 \beta-H S D 1$ with equilin as co-crystallized ligand, key residues, a flexible loop and the cofactor $\mathrm{NADP}^{+}$(PDB 1EQU).

In 2001, Hoffren et al. were the first to report structure-based pharmacophore models for the discovery of $17 \beta$-HSD1 inhibitors [129]. The pharmacophore models were validated to specifically recognize compounds possessing the structural and chemical features of steroids and flavonoids. Coumestrol displayed the most potent $17 \beta$-HSD1 inhibiting activity among the test compounds used for model validation. However, coumestrol also inhibited 17ß-HSD5 and is, therefore, not selective [130]. Unfortunately, the virtual hits were not confirmed by biological validation [129].

To support the development of therapeutic inhibitors, database creation for pharmacophore model validation should focus on selective inhibitors to increase model selectivity and sensitivity. Since steroidal inhibitors and natural phytoestrogens, including flavonoids, often exhibit cross-reactivity with other enzymes and hormone receptors involved in the steroidogenesis, non-steroidal scaffolds are more favorable for virtual screening and drug development. However, although highly selective inhibitors are needed for many therapeutic applications, polyvalent inhibitors acting on synergistic pathways may be advantageous in some situations.

The 17 $\beta$-HSD1 can be inhibited by several modes: competing reversibly and irreversibly with the natural substrate for its binding site, competing with $\mathrm{NADP}(\mathrm{H})$ for its binding site at the Rossmann fold or occupying the ligand and the cofactor binding site by so-called hybrid compounds consisting of a steroidal core and extended side-chains of $\mathrm{NADP}(\mathrm{H})$ moieties $[131,132]$. Since only crystal structures containing steroidal inhibitors were available at that time, Schuster and Nashev et al. generated structure-based pharmacophore models based on steroidal inhibitors [133]. They developed two pharmacophore models, representing, on one hand, reversible competitive inhibitors based on the 
steroidal core equilin (Figure 13A) and, on the other hand, hybrid inhibitors (Figure 13B). Whereas the first model was suggested to be suitable as a general screening tool, expecting many false positive hits, the hybrid model was more restrictive due to the unique scaffold of the underlying hybrid inhibitors. VS and subsequent in vitro validation of 14 selected compounds from the virtual hit list revealed, amongst others, two nonsteroidal hits with $\mathrm{IC}_{50}$ of $5.7 \mu \mathrm{M}$ and $19 \mu \mathrm{M}$, respectively. As mentioned above, the SDR enzymes share substantial structural similarity. For selectivity assessment, $11 \beta$-HSD1, 11 $\beta$-HSD2, 17 $\beta$-HSD2, 17 $\beta$-HSD3 and the AKR 17 $\beta$-HSD5 were tested. Two additional inhibitors were selective. One was a steroidal compound with an $\mathrm{IC}_{50}$ of $3.8 \mu \mathrm{M}$ for $11 \beta$-HSD1 and $47 \mu \mathrm{M}$ for $17 \beta-H S D 1$, and one a nonsteroidal $11 \beta-H S D 1$ inhibitor with $\mathrm{IC}_{50}$ of $6.2 \mu \mathrm{M}$ and comparable activity on $17 \beta-H S D 3$. These observations emphasize the importance of including structurally related enzymes for selectivity assessment. In addition to the biological selectivity assessment, Schuster and Nashev et al. applied pharmacophore models of structurally related enzymes as an alternative strategy to identify unspecific inhibitors [133]. These pharmacophores should act as initial filters to eliminate compounds with a low degree of selectivity that may exhibit off-target effects. Screening the compounds identified as actives for 11 $\beta$-HSD1 with their previously established selective 11 $\beta$-HSD1 pharmacophore model resulted in retrieving one hit [106]. By deleting the shape restriction, the second hit was found as well and, at the same time, showed higher best fit values than an inactive compound. Thus, screening of pharmacophore models of related enzymes may facilitate the discrimination of selective and nonselective inhibitors and the virtual hit selection for in vitro testing, similar to the study by Guasch et al. described above [56].

A

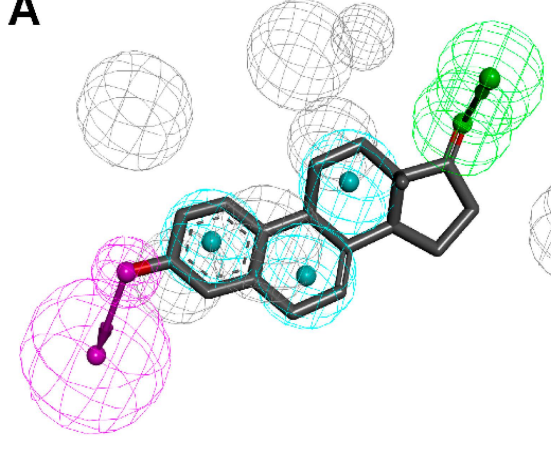

B

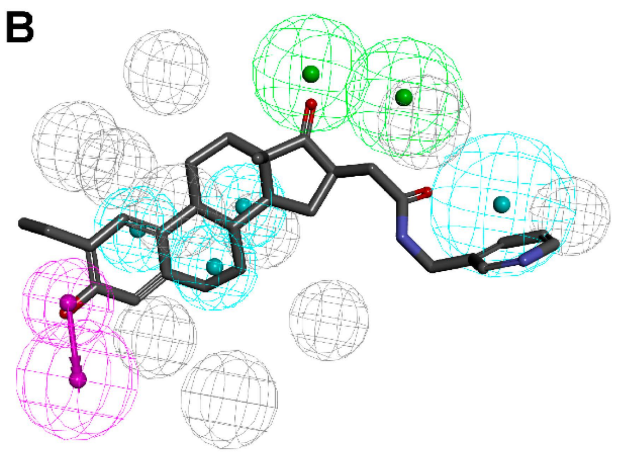

Figure 13. (A) 17 $\beta-H S D 1$ model based on the equilin crystal structure (PDB entry 1EQU [5]); (B) The potent inhibitor STX 1040 maps the hybrid 17ß-HSD1 pharmacophore model [133].

For pharmacophore model generation, Sparado et al. [134] superimposed five 17 $\beta$-HSD1 crystal structures, covering most of the chemical space occupied by the co-crystallized ligands. Performing a VS of an in-house compound library led to the identification of one virtual hit with moderate inhibitory activity against $17 \beta-H S D 1$. Application of the rigidification strategy, scaffold hopping and further SAR analysis resulted in two far more potent benzothiazole-scaffold-bearing inhibitors with $\mathrm{IC}_{50}$ in cell lysates of 44 and $243 \mathrm{nM}$, respectively. Both hits were selective against 17 $\beta$-HSD2. Furthermore, the less active compound still potently inhibited estrogen formation, with a comparable $\mathrm{IC}_{50}$ value to the lysates, in a human cell model endogenously expressing $17 \beta-\mathrm{HSD} 1$. The more potent compound showed pronounced affinity to bind to ER $\alpha$ and ER $\beta$. Depending on whether binding to $E R \alpha$ and ER $\beta$ results in agonistic or antagonistic effects, this could cause beneficial or adverse effects. Interestingly, although the two hits differ only in a carbonyl and amide bridge, respectively, binding mode investigations by docking showed a $180^{\circ}$ flipped orientation of the two molecules (Figure 14). The observation of a flipped binding mode was also discovered for corosolic acid and other triterpenoides in the binding pocket of $11 \beta$-HSD1 as described earlier [108]. A follow-up lead optimization study to improve activity and selectivity of the two compounds for in vivo applications, without the help of molecular modeling techniques, led to the discovery of two new lead compounds [135]. They showed selectivity over $17 \beta-\mathrm{HSD} 2$, no ER binding and promising activity in the intact cell model. 


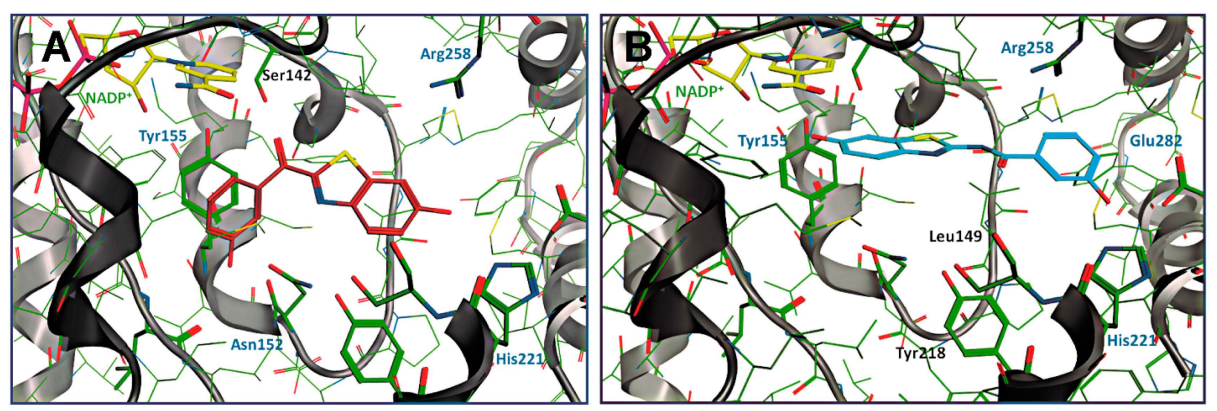

Figure 14. 17 $\beta-H S D 1$ in complex with the two hits from Sparado et al. [134], (doi:10.1371/journal. pone.0029252.g010, doi:10.1371/journal.pone.0029252.g011) showing a $180^{\circ}$ flipped orientation. $\mathrm{IC}_{50}$ values of $44 \mathrm{nM}(\mathbf{A})$ and $243 \mathrm{nM}(\mathbf{B})$.

Table 2 shows a summary of the prospective pharmacophore-based virtual screening studies and illustrates the scaffold-hopping potential for $17 \beta-H S D 1$ inhibitors.

Structure-based and ligand-based pharmacophore modeling was performed by Karkola et al. [136]. They generated four pharmacophore models with different methods based on a crystal structure, a relaxed crystal structure, alignment of thienopyrimidinone inhibitors, and a docked complex of $17 \beta$-HSD1 with a potent inhibitor. By VS, they found several compounds fitting into the active site of $17 \beta$-HSD1 without determining the activity of the hits. However, to validate these hits as $17 \beta$-HSD1 inhibitors, biological testing is needed. In addition, they could apply their differently generated pharmacophore models to calculate selectivity and sensitivity.

\subsection{2. $17 \beta$-Hydroxysteroid Dehydrogenase Type 2}

The oxidative inactivation of estradiol to estrone is predominantly catalyzed by $17 \beta-H S D 2$. Additionally, $17 \beta-\mathrm{HSD} 2$ is capable of converting testosterone into 4-androstene-3,17-dione (androstenedione), $5 \alpha$-dihydrotestosterone (DHT) into $5 \alpha$-androstanedione, 5 -androstene- $3 \beta, 17 \beta$-diol to DHEA, and $20 \alpha$-dihydroprogesterone into progesterone using the cofactor NAD+ $[137,138]$. The $17 \beta-H S D 2$ is expressed in various tissues such as bone, placenta, endometrium, breast, uterus, prostate, stomach, small intestine, and colon epithelium $[139,140]$. The current treatment options for osteoporosis bear several limitations. Since $17 \beta-H S D 2$ is expressed in osteoblasts, its inhibition may provide a new approach to treat osteoporosis by increasing the local availability of estradiol.

Since 17 $\beta$-HSD2 contains an N-terminal transmembrane anchor, the experimental 3D structure determination remains a challenge and, to date, still no crystal structure is available. Due to this lack, Vuorinen et al. constructed three ligand-based pharmacophore models as virtual screening filters [141]. Virtual hit-testing in a cell-free assay revealed seven out of 29 compounds with $\mathrm{IC}_{50}$ values against $17 \beta-H S D 2$ ranging between $0.24 \mu \mathrm{M}$ and $33 \mu \mathrm{M}$. Most of the active compounds represented phenylbenzene-sulfonamides and -sulfonates. With the new structural classes of 17 $\beta$-HSD2 inhibitors, they performed a SAR study using two different approaches: first, by a 2D similarity search without fitting the compounds into the pharmacophore models, and second, using a pharmacophore model for VS. From the 2D search, one out of 16 compounds inhibited $17 \beta-H S D 2$ with an $\mathrm{IC}_{50}$ of $3.3 \mu \mathrm{M}$, whereas the VS showed five out of 14 compounds with $\mathrm{IC}_{50}$ between 1-15 $\mu \mathrm{M}$. Selectivity of all active compounds was tested against inhibition of 17 $\beta$-HSD1, 17 $\beta-H S D 3,11 \beta-H S D 1$, and 11 $\beta-H S D 2$. The activity data of the phenylbenzene-sulfonamide and -sulfonate inhibitors revealed a phenolic hydroxyl group with hydrogen bond donor functionality, which was important for $17 \beta-H S D 2$ inhibition. This feature was confirmed by a ligand-based pharmacophore model that was developed based on several of the newly identified active compounds (Figure 15). Furthermore, to improve the initial pharmacophore model, a refinement database was created, including the original test set compounds and the newly identified inhibitors as well as the inactive compounds. The specificity of the model was increased by adding exclusion volumes. This approach is an important step to enhance a model's ability to enrich active compounds from a database. 


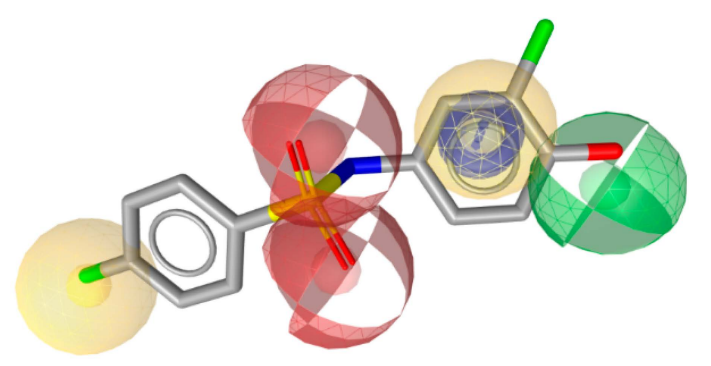

Figure 15. The selective $17 \beta-H S D 2$ model contains a HBD feature (green sphere), which is important for $17 \beta-H S D 2$ inhibitors such as the newly identified phenylbenzene-sulfonamide derivative 13 [141].

\subsubsection{7 $\beta$-Hydroxysteroid Dehydrogenase Type 3}

The $17 \beta-H S D 3$ is almost exclusively expressed in the testes and catalyzes the reduction of androstenedione to testosterone in the presence of NADPH [142]. Although 17 $\beta$-HSD3 is mainly found in the testes, there is evidence for $17 \beta-H S D 3$ mRNA up-regulation in prostate cancer [143]. Co-expression of $17 \beta-H S D 5$, catalyzing the same reaction, might limit the therapeutic efficacy of $17 \beta-H S D 3$ inhibitors and a combined treatment with inhibitors against both enzymes should be envisaged.

The enzyme is anchored through an $\mathrm{N}$-terminal transmembrane domain to the endoplasmic reticulum, and, like $17 \beta-H S D 2$, its catalytic domain faces the cytoplasmic compartment $[144,145]$. As for $17 \beta-H S D 2$, there is still no crystal structure available for the membrane protein 17 $\beta-H S D 3$.

A

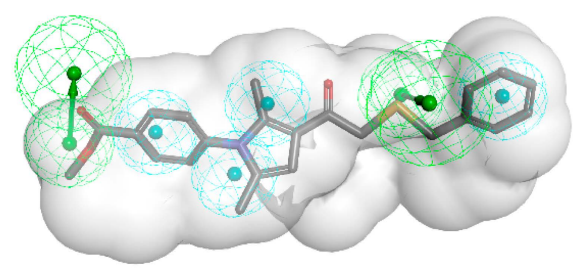

B

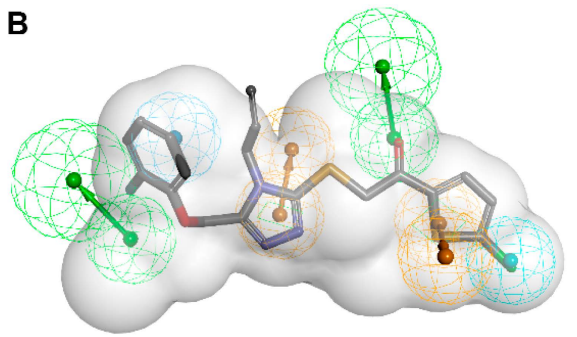

Figure 16. (A) The novel 17 $\beta$-HSD3 inhibitor 1-7 was identified with the steroid-based model consisting of two HBAs (green) and four $\mathrm{H}$ features (blue); (B) The non-selective inhibitor 2-2 mapped the nonsteroid-based 17 $\beta$-HSD3 model containing two HBAs, two AR (orange), one $\mathrm{H}$ and one H-AR feature [146].

Two ligand-based pharmacophore models, based on steroidal and nonsteroidal 17 $\beta$-HSD3 inhibitors, were developed by Schuster et al. [146] (Figure 16). These ligand-based models supported the observations by Vicker et al. of a highly hydrophobic active site of 17 $\beta$-HSD3 [147]. The models were then used to screen eight commercial databases and the hit list was further filtered prior to the selection of hits. Enzymatic tests showed that, from the steroid-based model, two out of 15 tested substances inhibited 17 $\beta$-HSD3, with one also inhibiting 17 $\beta$-HSD1 [146]. At the same time, three other compounds inhibiting the AKR 17 $\beta$-HSD5 were identified. The $17 \beta$-HSD5 is a multifunctional enzyme and, like $17 \beta-H S D 3$, catalyzes the conversion of androstenedione into testosterone. The most potent compound was not selective and also inhibited 11 $\beta-H S D 1$ and $11 \beta-H S D 2$. Similar results were obtained with the nonsteroidal model. The nonsteroidal model and its training compounds displayed several overlapping features with the lead compound identified earlier by Vicker et al. [147]; thus, the examination of their compounds for $17 \beta-H S D 5$ inhibitory activity would be interesting. These observations again emphasize the importance of including structurally related enzymes, independently of their enzymatic classes, for selectivity profiling. A summary of the 17 $\beta$-HSD3 pharmacophore-based virtual screening study presented by Schuster et al. is provided in Table 3 . 
Table 2. 17 $\beta$-HSD1 pharmacophore-based virtual screening studies summarized.

\begin{tabular}{|c|c|c|c|c|c|c|c|c|c|}
\hline \multirow{2}{*}{$\begin{array}{l}\text { Reference } \\
\text { Study Aim }\end{array}$} & \multirow{2}{*}{ Pharmacophore Model } & \multirow{2}{*}{$\begin{array}{l}\text { Database Used } \\
\text { for VS }\end{array}$} & \multicolumn{4}{|c|}{ Hits } & \multicolumn{3}{|c|}{ Biological Testing } \\
\hline & & & Most Active Hit & $\begin{array}{l}\text { Number of } \\
\text { Virtual Hits }\end{array}$ & $\begin{array}{c}\text { Tested } \\
\text { in Vitro }\end{array}$ & Actives & Assay & $\mathrm{IC}_{50}$ & Selectivity \\
\hline $\begin{array}{l}\text { Schuster and } \\
\text { Nashev } \text { et al. [133] } \\
17 \beta \text {-HSD1 } \\
\text { inhibitors }\end{array}$ & $\begin{array}{l}\text { Structure-based Using } \\
\text { LigandScout and } \\
\text { Catalyst 115R model }(4 \mathrm{H}, \\
\text { 2HBA, } 2 \text { HBD) Based on } \\
\text { a hybrid inhibitor }\end{array}$ & NCI, SPECS & & $1559 / 340042$ & 14 & $4, \mathrm{IC}_{50}<50 \mu \mathrm{M}$ & Lysates & $5.7-47 \mu \mathrm{M}$ & $\begin{array}{l}\text { Selective over } 17 \beta \text {-HSD2, } 17 \beta \text {-HSD3, } \\
17 \beta \text {-HSD5 and } 11 \beta \text {-HSD1, except one } \\
\text { compound, which was not selective } \\
\text { towards } 17 \beta \text {-HSD } 5 \text { and } 11 \beta \text {-HSD1 } \\
\text { However, one compound inhibited } \\
17 \beta \text {-HSD } 3 \text { and } 11 \beta \text {-HSD } 1 \text { but not } \\
17 \beta \text {-HSD1 and another compound } \\
\text { inhibited } 11 \beta \text {-HSD1 only }\end{array}$ \\
\hline $\begin{array}{l}\text { Sparado et al. [134] } \\
17 \beta \text {-HSD1 } \\
\text { inhibitors and lead } \\
\text { optimization }\end{array}$ & $\begin{array}{l}\text { Ligand-based By } \\
\text { superimposing } \\
\text { co-crystallized ligands } \\
\text { using MOE }(5 \mathrm{H}, 3 \mathrm{HBA}, \\
1 \mathrm{HBD}, 1 \mathrm{AR})\end{array}$ & $\begin{array}{l}\text { In-house } \\
\text { database }\end{array}$ & & $-/ 37$ & - & 1 & Cell-free & $\begin{array}{l}34 \% \text { Enzyme } \\
\text { inhibition with } \\
10 \mu \mathrm{M} \text { test } \\
\text { compounds }\end{array}$ & $\begin{array}{l}\text { Selectivity of optimized compounds } \\
\text { tested against } 17 \beta-\mathrm{HSD} 2 \text { and } \mathrm{ER} \alpha \\
\text { and ER } \beta\end{array}$ \\
\hline
\end{tabular}

Table 3. Summary of the $17 \beta-H S D 3$ pharmacophore-based virtual screening study.

\begin{tabular}{|c|c|c|c|c|c|c|c|c|c|}
\hline \multirow{2}{*}{$\begin{array}{l}\text { Reference } \\
\text { Study Aim }\end{array}$} & \multirow{2}{*}{$\begin{array}{l}\text { Pharmacophore } \\
\text { Model }\end{array}$} & \multirow{2}{*}{$\begin{array}{c}\text { Database Used } \\
\text { for VS }\end{array}$} & \multicolumn{4}{|c|}{ Hits } & \multicolumn{3}{|c|}{ Biological Testing } \\
\hline & & & Most Active Hit & $\begin{array}{l}\text { Number of Hits } \\
\text { after Filtering }\end{array}$ & $\begin{array}{l}\text { Tested } \\
\text { in Vitro }\end{array}$ & Actives & Assay & $\begin{array}{l}\text { Enzyme } \\
\text { Inhibition }\end{array}$ & Selectivity \\
\hline \multirow{3}{*}{$\begin{array}{l}\text { Schuster et al. [146] } \\
17 \beta \text {-HSD3 inhibitors }\end{array}$} & $\begin{array}{l}\text { Ligand-based } \\
\text { Using Catalyst }\end{array}$ & \multirow{3}{*}{$\begin{array}{l}\text { Asinex Gold and } \\
\text { Platinum, } \\
\text { ChemBridge, } \\
\text { Enamine, IF-Labs, } \\
\text { Maybridge, Specs, } \\
\text { Vitas-M }\end{array}$} & & $3921 / 1712102$ & 15 & 2 & \multirow{3}{*}{ Lysates } & $\begin{array}{l}\text { Inhibition }>40 \% \\
\text { with } 2 \text { uM test }\end{array}$ & \multirow{2}{*}{$\begin{array}{l}\text { Selective over } 17 \beta \text {-HSD2, } 17 \beta \text {-HSD4, } \\
17 \beta \text {-HSD7, } 11 \beta \text {-HSD1, and } 11 \beta \text {-HSD2, } \\
\text { acceptable selectivity over } 17 \beta \text {-HSD1 and } \\
17 \beta \text {-HSD5. However, several hits inhibited } \\
17 \beta \text {-HSD5 more potently than } 17 \beta \text {-HSD3 }\end{array}$} \\
\hline & $\begin{array}{l}\text { Model 1: steroidal } \\
\text { training compounds } \\
\text { (four H, two HBA) }\end{array}$ & & & & & & & $\begin{array}{l}\text { compounds as } \\
\text { threshold } 41.3 \% \\
\text { and } 50.8 \%\end{array}$ & \\
\hline & $\begin{array}{l}\text { Model 2: } \\
\text { non-steroidal } \\
\text { training compounds } \\
\text { (one H, two HBA, } \\
\text { two AR, one H-AR) }\end{array}$ & & & $8190 / 1712102$ & 16 & 2 & & $55.6 \%$ and $57.5 \%$ & $\begin{array}{l}\text { Selective over } 17 \beta \text {-HSD2, } 17 \beta \text {-HSD4, } \\
17 \beta \text {-HSD7, and } 11 \beta \text {-HSD2, acceptable } \\
\text { selectivity over } 17 \beta \text {-HSD1 } \\
\text { One hit was not selective over 17 } \beta \text {-HSD5 } \\
\text { and the other not over } 11 \beta \text {-HSD1. However, } \\
\text { several hits inhibited } 17 \beta \text {-HSD5 more } \\
\text { potently than } 17 \beta \text {-HSD3 }\end{array}$ \\
\hline
\end{tabular}




\subsection{Applications in Toxicology}

\subsubsection{Anti-Target Screening}

Although the actual virtual screening process is analogous to lead identification, anti-target screening pursues a different aim. Lead identification focuses on the discovery of ligands for therapeutically relevant targets, whereas anti-target screening aims at predicting the interaction of molecules with macromolecules mediating potentially harmful effects (so-called anti-targets). These investigations support the identification of (serious) adverse events already at an early stage in drug development. This strategy is powerful, as recently shown by Kratz et al. [148], who successfully applied pharmacophore models to identify inhibitors of the human ether-a-go-go-related gene (hERG) potassium channel, thereby predicting the cardiotoxic potential of the investigated molecules [148].

\subsubsection{Parallel Screening}

Parallel screening represents an extension to lead identification and anti-target screening protocols. It investigates not a single target but a whole collection of macromolecules with the aim of obtaining activity profiles of compounds of interest in order to prioritize further investigation. Thus, the focus of this technique shifts from the target of interest to the compound of interest, which is screened against a collection of pharmacophores, representing a plethora of different targets. Parallel screening has the potential to identify macromolecular interaction partners of the investigated molecule, thereby providing novel insight into its biological activities. These activities may include beneficial (i.e., therapeutic) and harmful (i.e., toxic) effects. Therefore, the results support the evaluation of a compound both with regard to the occurrence of adverse events and potential novel application fields (whenever this aspect represents the main aim of the parallel screening, this technique is also referred to as drug repurposing or drug repositioning). In the attempt to explore the biological activity of leoligin, a lignan isolated from the alpine plant Edelweiss (Leontopodium alpinum), the compound was screened against the Inte:Ligand pharmacophore collection in the course of a parallel screening [149]. Among the proposed targets, wascholesteryl ester transfer protein (CETP), a target involved in lipoprotein metabolism, was shown to be activated by leoligin in subsequent experimental testing. On the other side, leoligin was also predicted to inhibit the cytochrome P450 (CYP) isoforms 1A2, 2C9, and 3A4 [150], which are involved in the metabolic clearance of exogenous compounds. While it was not active on CYP1A2, it was a weak inhibitor on CYP2C9, and a sub-micromolar IC $_{50}$ was determined for CYP3A4 [150]. Inhibition of CYP enzymes can cause severe drug-drug interactions that may lead to serious adverse effects and eventually require the termination of a drug development project. Accordingly, both potentially beneficial (CETP activation) and potentially harmful (CYP inhibition) effects can be detected during a parallel screening.

\subsubsection{Examples}

There is a great demand for improved methods for the safety assessment of man-made chemicals released into the environment $[68,151]$. Endocrine-disrupting chemicals (EDCs) are exogenous substances interfering with hormone synthesis, metabolism and/or hormonal regulation, thereby adversely affecting human health by contributing to developmental and reproductive disorders, cardio-metabolic diseases, cancer, and immune-related diseases and psychiatric disorders [152]. EDCs include substances used in agriculture, industrial production, dyes, food preservatives, or body care products and cosmetics. Several SDRs are essentially involved in the control of the local availability of active glucocorticoids, androgens and estrogens, and these enzymes should therefore be considered in the assessment of potential EDCs. In silico tools are well established in the drug discovery process; however, they can also display a valuable part in the identification of new EDCs or the mechanism of action of known EDCs [68].

Nashev and Vuorinen et al. [70] reported a pharmacophore-based virtual screening using a

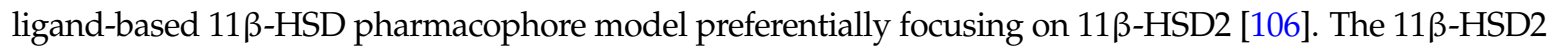


protects the mineralocorticoid receptor (MR) from activation by cortisol and renders specificity for the much less abundant aldosterone to activate this receptor. Genetic defects of this enzyme cause the syndrome of apparent mineralocorticoid excess (AME), characterized by hypokalemia, hypernatremia, and severe hypertension $[153,154]$. In addition, placental $11 \beta-H S D 2$ protects the fetus from enhanced maternal cortisol exposure [155,156]. Therefore, disrupting corticosteroid action by EDCs can be expected to cause substantial adverse health effects. VS of an EDC database predicted 29 compounds fitting into the model of which five hits were selected for biological evaluation. Two compounds were found to inhibit $11 \beta \mathrm{HSD} 2$, the silane coupling agent AB110873 and the antibiotic lasalocid, with $\mathrm{IC}_{50}$ values of $6.1 \mu \mathrm{M}$ and $14 \mu \mathrm{M}$, respectively. The silane AB110873 is widely used as a rubber additive for the production of tires, mechanical goods, or shoe soles and lasalocid is used as a feed additive for the prevention of infections in the breeding of chicken and turkeys. Docking studies were implemented to understand the binding mode of AB110873 in 11ß-HSD2 (Figure 17) and MR.

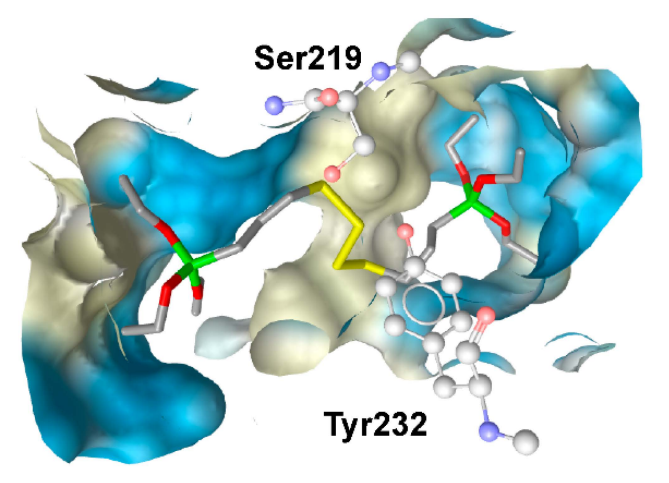

Figure 17. Docking of silane into the homology model of 11ß-HSD2 [78] suggests hydrogen bond interactions with Ser219 and Tyr232 [70].

Genetic defects resulting in 17 $\beta$-HSD3 deficiency cause 46,XY disorder of sex development $[142,157,158]$. Inhibition of $17 \beta$-HSD3 activity by EDCs might reduce plasma testosterone levels, thereby interfering with male sexual development and contributing to male reproductive disorders. To identify potential EDCs inhibiting 17 $\beta-H S D 3$, Nashev and Schuster et al. generated a ligand-based pharmacophore model [74]. VS of an EDC database predicted several organic UV filters containing a benzophenone as a bioactive chemical scaffold. UV filters are a structurally diverse class of chemicals widely used in sunscreens and cosmetics as well as plastic additives. In vitro testing of selected virtual hits and similar environmentally relevant derivatives led to the identification of benzophenone-1 (BP-1) as the most potent $17 \beta$-HSD3 inhibitor with an $\mathrm{IC}_{50}$ of $1.05 \mu \mathrm{M}$ in intact cells. BP-2,3-benzylidene camphor (3-BC) and 4-methylbenzylidene camphor (4-MBC) moderately inhibited $17 \beta-\mathrm{HSD} 3$ with $\mathrm{IC}_{50}$ values between $10.7 \mu \mathrm{M}$ and $33.3 \mu \mathrm{M}$, but showed substantial inhibitory activity on $17 \beta$-HSD2 with $\mathrm{IC}_{50}$ between $5.9 \mu \mathrm{M}$ and $10.3 \mu \mathrm{M}$. Importantly, the most active compound, BP-1, as well as 3-BC and 4-MBC were not included in the initial virtual hit list but added to the biological testing due to their use as UV filters. Hence, VS displays an initial filter for the identification of potential EDC compound classes and aims at prioritizing the compounds to be included for biological investigations. In analogy to the drug discovery process, it is important to test structurally related enzymes in order to know whether they are affected by a given EDC. Importantly, major metabolites should also be included in the analysis. For example, BP-3 showed no activity against 17 $\beta-$ HSD3, but it is demethylated in vivo to the potent inhibitor BP-1 [159]. To explain the differential inhibitory activities of the tested UV filters, Schuster and Nashev conducted pharmacophore-based SAR studies, suggesting that the ether group on BP-3 and BP-8 instead of a hydroxyl group on BP-1 and BP-2 was the reason for the loss of activity of BP-3 and BP-8 (Figure 18). To further study the toxicological relevance of $17 \beta-H S D 3$ inhibition by BP-1, concentrations reached in vivo, especially in the testes, need to be determined. 


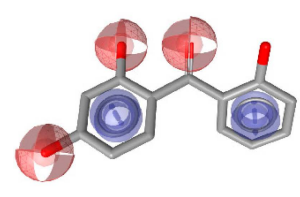

$\mathrm{BP}-1$
$\mathrm{IC}_{50}=1.05 \mu \mathrm{M}$

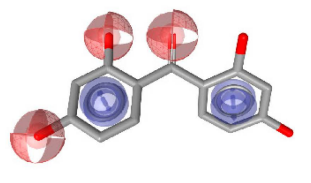

$\mathrm{BP}-2$
$\mathrm{IC}_{50}=18.1 \mu \mathrm{M}$

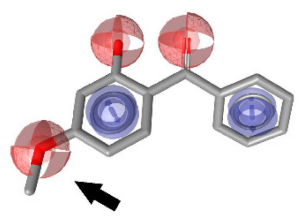

BP-3 $93 \%$ rest activity*

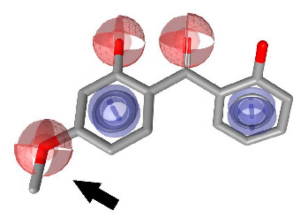

BP-8

$86 \%$ rest activity*

Figure 18. SAR analysis revealed that the etherification of the hydroxyl group (as indicated by the arrows) was responsible for the loss of activity observed for BP-3 and BP-8 [74]. * Remaining enzyme activity at a compound concentration of $20 \mu \mathrm{M}$ compared to vehicle control.

\section{Limitations}

As with every method, pharmacophore modeling and pharmacophore-based virtual screening also have their limits. A recent study compared the performances of two pharmacophore modeling programs, LigandScout and Discovery Studio, on the identification of novel cyclooxygenase inhibitors [160]. Intriguingly, although both programs succeeded in the identification of novel bioactive molecules, the virtual hit lists retrieved with the two tools were highly complementary. It is of note that not a single overlap in the hit lists was observed, even when the identical crystal structure of a ligand-target complex was employed for model generation. This illustrates that neither of the two programs was capable of comprehensively covering the active space and that models from different programs need to be combined whenever a more complete retrieval of active molecules is required. The authors suggested that the reasons for this finding may be found in the different screening algorithms and feature definitions deployed by the programs.

Feature definitions can be improved in general, as highlighted by the treatment of halogens. Some pharmacophore modeling programs consider halogens solely as hydrophobic moieties in the default settings [7,8,161]. LigandScout, in addition, matches fluorine to HBA features [6]. In 2013, a study by Sirimulla et al. [162] revealed that in many ligand-target complexes, halogens participate in strong halogen bond formation, e.g., with aromatic rings, and thereby considerably contribute to the interaction between the ligand and the target. These types of interactions, although often employed by medicinal chemists to improve the binding affinity of compounds [162], are not yet implemented in common pharmacophore-based virtual screening tools.

A major limitation, not only for pharmacophore modeling but for virtual screening tools in general, is the fact that the quality of a pharmacophore model critically depends on the data employed for model generation, refinement, and theoretical validation. Many public data repositories are available that can be explored to build a model. However, caution is required as, apparently, parts of the data are erroneous. Fourches et al. investigated six different datasets, and after curation, up to $10 \%$ of the original structures were removed [163]. Besides several other preventive measures, the authors suggest to include a final manual inspection step to check the structures of the input compounds. We fully support this recommendation and would even go one step further: Not only the structures of the compounds included in the modeling dataset need to be critically evaluated, but also the annotated biological data. This starts with inclusion/exclusion criteria for appropriate/inappropriate testing systems applied to determine the biological activity of a compound (for example, data obtained from intact cell assays or from animal tissue preparations are of limited use for human enzyme models), the application of suitable activity cut-offs (distinguishing between specific and unspecific effects, depending on the investigated target), and ends at a critical comparison with the original literature as errors can also happen during the transfer of data to depositories. These procedures may be quite elaborate; nevertheless, they are crucial for the generation of high quality models and every modeler is well advised to carefully review the data on which the models are based.

Another limitation is a lack of compounds confirmed as inactive for a specific target. Results on proven inactives for model validation are often not accessible because, unfortunately, negative 
results are rarely published. The information from confirmed inactive compounds is important for the balancing between selectivity and sensitivity of a model during the validation step. In the drug development process, restrictive models are required because, finally, only one or a few lead compounds are selected for further optimization steps, whereas in a toxicology screening, it is important to correctly find preferably all of the potentially harmful substances. Albeit considerably more successful than random screening, the success rate of VS may still be a limiting factor for toxicological projects. However, it has the ability to identify structural compound classes that then can be further evaluated. Obviously, the database used for VS might be self-limiting as not all potential active compounds are included.

One caveat of pharmacophore modeling is that a modeler needs to be aware of concerns about detailed interaction patterns of the active compounds in the dataset. Although high quality experimental data confirming their binding and activity may be available for these ligands, the exact binding site is still not clearly defined for most of them. Many molecules may occupy a similar yet slightly different part of the binding pocket, e.g., compared to the co-crystallized ligand in an X-ray crystallographic complex employed for model generation. Accordingly, the interaction patterns may differ. This factor is even more pronounced in ligands affecting the function of a protein by binding to allosteric sites, disrupting conformational changes, or interfering with post-translational modifications. Similar concerns also apply for the experimental validation of the in silico predictions, as it is, in the end, often not known whether the newly identified compounds indeed exert the predicted binding mode [164]. An X-ray crystal structure of the ligand-target complex would provide the ultimate confirmation of the exact interaction patterns; however, 3D structure resolution of transmembrane proteins by crystallization remains difficult. Several SDRs belong to this class of proteins such as, for instance, $11 \beta \mathrm{HSD} 2,17 \beta \mathrm{HSD} 2$, and 17 $\beta$ HSD3. For these proteins, structure-based pharmacophore modeling is currently not possible, and homology modeling remains challenging due to the low sequence similarity of SDRs. However, for these cases, ligand-based pharmacophore modeling displays an elegant solution.

Pharmacophore-based VS proved to be a powerful tool to support drug discovery and development, especially concerning the enrichment of active molecules among test compounds. Nevertheless, expectations concerning the results of VS need to remain realistic. Although sometimes potent compounds are discovered via VS, the majority of virtual hits usually display only weak activity. For this concern, the initial virtual hits from VS should be considered similar to initial experimental hits discovered in a HTS campaign, which also require further chemical optimization steps to develop to potential drug candidates [164].

\section{Conclusions}

The current work summarizes prospective pharmacophore-based studies conducted in the field of steroid biology, with special focus on SDRs, and highlights success stories reported in this area. Pharmacophore models are suitable to address a wide range of issues relevant for both drug discovery and toxicology. This is of special relevance for SDRs, because members of this target class are both associated with therapeutic value (e.g., 17 $\beta$-HSD1 inhibition for the treatment of hormone-sensitive cancers) and toxicological liabilities (disruption of 11ß-HSD2 actions). Although the method itself still has room for improvement as pointed out in the "Limits" section, the caveats associated with pharmacophore modeling largely also apply for other virtual screening techniques. In addition, in case of a lack of available structural data on macromolecular targets, ligand-based modeling strategies offer a useful alternative. The identification of structurally diverse molecules may, to a certain extent, be restricted to the data employed for model generation and refinement. However, the extraction of crucial interactions and their representation via abstract chemical features proved to be a powerful approach to step beyond the initial chemical space. As highlighted in this review, pharmacophore-based VS is a valuable scaffold-hopping tool. Importantly, this allows for the application of pharmacophore-based virtual screening also for compound classes that do not fall into the category of "small drug-like 
compounds" or whose properties differ from that of synthetic compounds: For example, natural products provide a vast resource for bioactive compounds that can be exploited for therapeutic purposes. On the other hand, the in silico-driven investigation of environmental chemicals, which often chemically differ from drug-like molecules, facilitates the rapid identification of potentially harmful compounds that need to be prioritized for experimental evaluation. Given the many application fields of pharmacophore-based virtual screening and the successful examples summarized in this review, an increasing number of studies, also in the field of SDR research, can be expected in the future.

Acknowledgments: We are grateful for financial support from the Austrian Science Fund (FWF, project P26782 "Safety of environmental chemicals". A.O. was supported as Chair for Molecular and Systems Toxicology by the Novartis Research Foundation.

Author Contributions: Teresa Kaserer, Katharina R. Beck, Muhammad Akram, Alex Odermatt and Daniela Schuster were involved in literature search, data analysis and interpretation, and writing of the manuscript.

Conflicts of Interest: The authors declare no conflict of interest.

\section{Abbreviations}

The following abbreviations are used in this manuscript:

$\begin{array}{ll}\text { 3-BC } & \text { 3-benzylidene camphor } \\ \text { 4-MBC } & \text { 4-methylbenzylidene camphor } \\ \text { AKR } & \text { aldo-keto reductase } \\ \text { AME } & \text { apparent mineralocorticoid excess } \\ \text { AR } & \text { aromatic features } \\ \text { BP } & \text { benzophenone } \\ \text { CETP } & \text { cholesterylester transfer protein } \\ \text { CYP } & \text { cytochrome P450 } \\ \text { DHEA } & \text { dehydroepiandrosterone } \\ \text { DHT } & \text { 5 } \alpha \text {-dihydrotestosterone } \\ \text { DUD-E } & \text { Directory of Useful Decoys, Enhanced } \\ \text { EDCs } & \text { endocrine disrupting chemicals } \\ \text { ER } & \text { estrogen receptor } \\ \text { GA } & \text { glycyrrhetinic acid } \\ \text { H } & \text { hydrophobic feature } \\ \text { HBA } & \text { hydrogen bond acceptor } \\ \text { HBD } & \text { hydrogen bond donor } \\ \text { hERG } & \text { human ether-a-go-go related gene } \\ \text { HSD } & \text { hydroxysteroid dehydrogenase } \\ \text { HTS } & \text { high-throughput screening } \\ \text { IUPAC } & \text { International Union of Pure and Applied Chemistry } \\ \text { MD } & \text { molecular dynamics } \\ \text { MOE } & \text { Molecular Operating Environment } \\ \text { MR } & \text { mineralocorticoid receptor } \\ \text { NADP } & \text { nicotinamide adenine dinucleotide phosphate } \\ \text { PAINS } & \text { Pan-Assay Interference Compounds } \\ \text { PDB } & \text { Protein Data Bank } \\ \text { PPAR } \gamma & \text { peroxisome proliferator-activated receptor } \gamma \\ \text { ROC-AUC } & \text { area under the receiver operating characteristics curve } \\ \text { SAR } & \text { structure-activity relationship } \\ \text { SDR } & \text { short-chain dehydrogenase/reductase } \\ & \end{array}$


VS

virtual screening

XVols exclusion volumes

\section{References}

1. Ehrlich, P. Über die constitution des diphtheriegiftes. Deutsch. Med. Wochschr. 1898, 24, 597-600. [CrossRef]

2. Güner, O.F.; Bowen, J.P. Setting the record straight: The origin of the pharmacophore concept. J. Chem. Inf. Model. 2014, 54, 1269-1283. [CrossRef] [PubMed]

3. Schueler, F.W. Chemobiodynamics and Drug Design; McGraw-Hill: New York, NY, USA, 1960.

4. Wermuth, G.; Ganellin, C.R.; Lindberg, P.; Mitscher, L.A. Glossary of terms used in medicinal chemistry (iupac recommendations 1998). Pure Appl. Chem. 1998, 70, 1129-1143. [CrossRef]

5. Sawicki, M.W.; Erman, M.; Puranen, T.; Vihko, P.; Ghosh, D. Structure of the ternary complex of human $17 \beta$-hydroxysteroid dehydrogenase type 1 with 3-hydroxyestra-1,3,5,7-tetraen-17-one (equilin) and NADP ${ }^{+}$. Proc. Natl. Acad. Sci. USA 1999, 96, 840-845. [CrossRef] [PubMed]

6. Wolber, G.; Langer, T. Ligandscout: 3-D pharmacophores derived from protein-bound ligands and their use as virtual screening filters. J. Chem. Inf. Model. 2005, 45, 160-169. [CrossRef] [PubMed]

7. Dassault Systèmes BIOVIA. Discovery Studio Modeling Environment; Dassault Systèmes: San Diego, CA, USA, 2015.

8. Molecular Operating Environment (MOE); Chemical Computing Group Inc.: Montreal, QC, Canada, 2015.

9. Berman, H.; Westbrook, J.; Feng, Z.; Gilliland, G.; Bhat, T.; Weissig, H.; Shindyalov, I.; Bourne, P. The Protein Data Bank. Nucleic Acids Res. 2000, 28, 235-242. [CrossRef] [PubMed]

10. Sutter, J.; Li, J.; Maynard, A.J.; Goupil, A.; Luu, T.; Nadassy, K. New features that improve the pharmacophore tools from accelrys. Curr. Comput.-Aided Drug Des. 2011, 7, 173-180. [CrossRef] [PubMed]

11. Kitchen, D.B.; Decornez, H.; Furr, J.R.; Bajorath, J. Docking and scoring in virtual screening for drug discovery: Methods and applications. Nat. Rev. Drug Discov. 2004, 3, 935-949. [CrossRef] [PubMed]

12. Shen, J.; Zhang, W.; Fang, H.; Perkins, R.; Tong, W.; Hong, H. Homology modeling, molecular docking, and molecular dynamics simulations elucidated alpha-fetoprotein binding modes. BMC Bioinform. 2013, 14 (Suppl. 14), S6.

13. Bey, E.; Marchais-Oberwinkler, S.; Kruchten, P.; Frotscher, M.; Werth, R.; Oster, A.; Algül, O.; Neugebauer, A.; Hartmann, R.W. Design, synthesis and biological evaluation of bis(hydroxyphenyl) azoles as potent and selective non-steroidal inhibitors of $17 \beta$-hydroxysteroid dehydrogenase type 1 (17 $\beta$-HSD1) for the treatment of estrogen-dependent diseases. Bioorg. Med. Chem. 2008, 16, 6423-6435. [CrossRef] [PubMed]

14. Oster, A.; Hinsberger, S.; Werth, R.; Marchais-Oberwinkler, S.; Frotscher, M.; Hartmann, R.W. Bicyclic substituted hydroxyphenylmethanones as novel inhibitors of $17 \beta$-hydroxysteroid dehydrogenase type 1 (17ß-hsd1) for the treatment of estrogen-dependent diseases. J. Med. Chem. 2010, 53, 8176-8186. [CrossRef] [PubMed]

15. Akram, M.; Kaserer, T.; Schuster, D. Pharmacophore modeling and screening. In In silico Drug Discovery and Design: Theory, Methods, Challenges and Applications; Cavasotto, C., Ed.; CRC Press: Boca Raton, FL, USA, 2015; pp. 123-153.

16. Vuorinen, A.; Schuster, D. Methods for generating and applying pharmacophore models as virtual screening filters and for bioactivity profiling. Methods 2015, 71, 113-134. [CrossRef] [PubMed]

17. Lagarde, N.; Zagury, J.-F.; Montes, M. Benchmarking data sets for the evaluation of virtual ligand screening methods: Review and perspectives. J. Chem. Inf. Model. 2015, 55, 1297-1307. [CrossRef] [PubMed]

18. Heikamp, K.; Bajorath, J. Comparison of confirmed inactive and randomly selected compounds as negative training examples in support vector machine-based virtual screening. J. Chem. Inf. Model. 2013, 53, 1595-1601. [CrossRef] [PubMed]

19. Gaulton, A.; Bellis, L.J.; Bento, A.P.; Chambers, J.; Davies, M.; Hersey, A.; Light, Y.; McGlinchey, S.; Michalovich, D.; Al-Lazikani, B.; et al. Chembl: A large-scale bioactivity database for drug discovery. Nucleic Acids Res. 2011, 40, D1100-D1107. [CrossRef] [PubMed]

20. Wishart, D.S.; Knox, C.; Guo, A.C.; Shrivastava, S.; Hassanali, M.; Stothard, P.; Chang, Z.; Woolsey, J. Drugbank: A comprehensive resource for in silico drug discovery and exploration. Nucleic Acids Res. 2006, 34, D668-D672. [CrossRef] [PubMed] 
21. Williams, A.J.; Harland, L.; Groth, P.; Pettifer, S.; Chichester, C.; Willighagen, E.L.; Evelo, C.T.; Blomberg, N.; Ecker, G.; Goble, C.; et al. Open phacts: Semantic interoperability for drug discovery. Drug Discov. Today 2012, 17, 1188-1198. [CrossRef] [PubMed]

22. Dix, D.J.; Houck, K.A.; Martin, M.T.; Richard, A.M.; Setzer, R.W.; Kavlock, R.J. The toxcast program for prioritizing toxicity testing of environmental chemicals. Toxicol. Sci. 2007, 95, 5-12. [CrossRef] [PubMed]

23. Kavlock, R.J.; Austin, C.P.; Tice, R.R. Toxicity testing in the 21st century: Implications for human health risk assessment. Risk Anal. 2009, 29, 485-487. [CrossRef] [PubMed]

24. Wang, Y.; Xiao, J.; Suzek, T.O.; Zhang, J.; Wang, J.; Zhou, Z.; Han, L.; Karapetyan, K.; Dracheva, S.; Shoemaker, B.A.; et al. Pubchem's bioassay database. Nucleic Acids Res. 2012, 40, D400-D412. [CrossRef] [PubMed]

25. Verdonk, M.L.; Berdini, V.; Hartshorn, M.J.; Mooij, W.T.M.; Murray, C.W.; Taylor, R.D.; Watson, P. Virtual screening using protein-ligand docking: Avoiding artificial enrichment. J. Chem. Inf. Comput. Sci. 2004, 44, 793-806. [CrossRef] [PubMed]

26. Kirchmair, J.; Markt, P.; Distinto, S.; Wolber, G.; Langer, T. Evaluation of the performance of 3d virtual screening protocols: Rmsd comparisons, enrichment assessments, and decoy selection-What can we learn from earlier mistakes? J. Comput. Aided Mol. Des. 2008, 22, 213-228. [CrossRef] [PubMed]

27. Huang, N.; Shoichet, B.K.; Irwin, J.J. Benchmarking sets for molecular docking. J. Med. Chem. 2006, 49, 6789-6801. [CrossRef] [PubMed]

28. Mysinger, M.M.; Carchia, M.; Irwin, J.J.; Shoichet, B.K. Directory of useful decoys, enhanced (DUD-E): Better ligands and decoys for better benchmarking. J. Med. Chem. 2012, 55, 6582-6594. [CrossRef] [PubMed]

29. Vuorinen, A.; Nashev, L.G.; Odermatt, A.; Rollinger, J.M.; Schuster, D. Pharmacophore model refinement for $11 \beta$-xydroxysteroid dehydrogenase inhibitors: Search for modulators of intracellular glucocorticoid concentrations. Mol. Inf. 2014, 33, 15-25. [CrossRef]

30. Güner, F.; Henry, R. Metric for analyzing hit-lists and pharmacophores. In Pharmacophore Perception, Development, and Use in Drug Design; Güner, O.F., Ed.; International University Line: La Jolla, CA, USA, 2000; pp. 193-212.

31. Triballeau, N.; Acher, F.; Brabet, I.; Pin, J.-P.; Bertrand, H.-O. Virtual screening workflow development guided by the "receiver operating characteristic" curve approach. Application to high-throughput docking on metabotropic glutamate receptor subtype 4. J. Med. Chem. 2005, 48, 2534-2547. [CrossRef] [PubMed]

32. Braga, R.C.; Andrade, C.H. Assessing the performance of $3 \mathrm{~d}$ pharmacophore models in virtual screening: How good are they? Curr. Top. Med. Chem. 2013, 13, 1127-1138. [CrossRef] [PubMed]

33. Bajorath, J. Integration of virtual and high-throughput screening. Nat. Rev. Drug Discov. 2002, 1, $882-894$. [CrossRef] [PubMed]

34. Tanrikulu, Y.; Krüger, B.; Proschak, E. The holistic integration of virtual screening in drug discovery. Drug Discov. Today 2013, 18, 358-364. [CrossRef] [PubMed]

35. Schuster, D.; Spetea, M.; Music, M.; Rief, S.; Fink, M.; Kirchmair, J.; Schütz, J.; Wolber, G.; Langer, T.; Stuppner, H.; et al. Morphinans and isoquinolines: Acetylcholinesterase inhibition, pharmacophore modeling, and interaction with opioid receptors. Bioorganic Med. Chem. 2010, 18, 5071-5080. [CrossRef] [PubMed]

36. Polgár, T.; Baki, A.; Szendrei, G.I.; Keserüu, G.M. Comparative virtual and experimental high-throughput screening for glycogen synthase kinase-3 $\beta$ inhibitors. J. Med. Chem. 2005, 48, 7946-7959. [CrossRef] [PubMed]

37. Doman, T.N.; McGovern, S.L.; Witherbee, B.J.; Kasten, T.P.; Kurumbail, R.; Stallings, W.C.; Connolly, D.T.; Shoichet, B.K. Molecular docking and high-throughput screening for novel inhibitors of protein tyrosine phosphatase-1b. J. Med. Chem. 2002, 45, 2213-2221. [CrossRef] [PubMed]

38. Wu, B.; Gao, J.; Wang, M. Development of a complex scintillation proximity assay for high throughput screening of ppar[gamma] modulators. Acta Pharmacol. Sin. 2005, 26, 339-344. [CrossRef] [PubMed]

39. Murgueitio, M.S.; Henneke, P.; Glossmann, H.; Santos-Sierra, S.; Wolber, G. Prospective virtual screening in a sparse data scenario: Design of small-molecule tlr2 antagonists. ChemMedChem 2014, 9, 813-822. [CrossRef] [PubMed]

40. Krautscheid, Y.; Senning, C.J.Å.; Sartori, S.B.; Singewald, N.; Schuster, D.; Stuppner, H. Pharmacophore modeling, virtual screening, and in vitro testing reveal haloperidol, eprazinone, and fenbutrazate as neurokinin receptors ligands. J. Chem. Inf. Model. 2014, 54, 1747-1757. [CrossRef] [PubMed] 
41. Joung, J.Y.; Lee, H.Y.; Park, J.; Lee, J.-Y.; Chang, B.H.; No, K.T.; Nam, K.-Y.; Hwang, J.S. Identification of novel rab27a/melanophilin blockers by pharmacophore-based virtual screening. Appl. Biochem. Biotechnol. 2014, 172, 1882-1897. [CrossRef] [PubMed]

42. Lu, P.; Wang, Y.; Ouyang, P.K.; She, J.; He, M. 3d-qsar based pharmacophore modeling and virtual screening for identification of novel g protein-coupled receptor 40 agonists. Curr. Comput.-Aided Drug Des. 2015, 11, 51-56. [CrossRef] [PubMed]

43. Singh, N.; Tiwari, S.; Srivastava, K.K.; Siddiqi, M.I. Identification of novel inhibitors of mycobacterium tuberculosis pkng using pharmacophore based virtual screening, docking, molecular dynamics simulation, and their biological evaluation. J. Chem. Inf. Model. 2015, 55, 1120-1129. [CrossRef] [PubMed]

44. Temml, V.; Voss, C.V.; Dirsch, V.M.; Schuster, D. Discovery of new liver x receptor agonists by pharmacophore modeling and shape-based virtual screening. J. Chem. Inf. Model. 2014, 54, 367-371. [CrossRef] [PubMed]

45. Ha, H.; Debnath, B.; Odde, S.; Bensman, T.; Ho, H.; Beringer, P.M.; Neamati, N. Discovery of novel cxcr2 inhibitors using ligand-based pharmacophore models. J. Chem. Inf. Model. 2015, 55, 1720-1738. [CrossRef] [PubMed]

46. Lepailleur, A.; Freret, T.; Lemaître, S.; Boulouard, M.; Dauphin, F.; Hinschberger, A.; Dulin, F.; Lesnard, A.; Bureau, R.; Rault, S. Dual histamine h3r/serotonin 5-ht4r ligands with antiamnesic properties: Pharmacophore-based virtual screening and polypharmacology. J. Chem. Inf. Model. 2014, 54, 1773-1784. [CrossRef] [PubMed]

47. Ferreira, R.J.; dos Santos, D.J.V.A.; Ferreira, M.-J.U.; Guedes, R.C. Toward a better pharmacophore description of $p$-glycoprotein modulators, based on macrocyclic diterpenes from euphorbia species. J. Chem. Inf. Model. 2011, 51, 1315-1324. [CrossRef] [PubMed]

48. Flohr, S.; Kurz, M.; Kostenis, E.; Brkovich, A.; Fournier, A.; Klabunde, T. Identification of nonpeptidic urotensin ii receptor antagonists by virtual screening based on a pharmacophore model derived from structure-activity relationships and nuclear magnetic resonance studies on urotensin ii. J. Med. Chem. 2002, 45, 1799-1805. [CrossRef] [PubMed]

49. Hessler, G.; Baringhaus, K.-H. The scaffold hopping potential of pharmacophores. Drug Discov. Today Technol. 2010, 7, e263-e269. [CrossRef] [PubMed]

50. Goldmann, D.; Pakfeifer, P.; Hering, S.; Ecker, G.F. Novel scaffolds for modulation of trpv1 identified with pharmacophore modeling and virtual screening. Future Med. Chem. 2015, 7, 243-256. [CrossRef] [PubMed]

51. Ayan, D.; Maltais, R.; Roy, J.; Poirier, D. A new nonestrogenic steroidal inhibitor of 17beta-hydroxysteroid dehydrogenase type i blocks the estrogen-dependent breast cancer tumor growth induced by estrone. Mol. Cancer Ther. 2012, 11, 2096-2104. [CrossRef] [PubMed]

52. Delvoux, B.; D’Hooghe, T.; Kyama, C.; Koskimies, P.; Hermans, R.J.; Dunselman, G.A.; Romano, A. Inhibition of type 1 17beta-hydroxysteroid dehydrogenase impairs the synthesis of 17 beta-estradiol in endometriosis lesions. J. Clin. Endocr. Metab. 2014, 99, 276-284. [CrossRef] [PubMed]

53. Marchais-Oberwinkler, S.; Henn, C.; Moller, G.; Klein, T.; Negri, M.; Oster, A.; Spadaro, A.; Werth, R.; Wetzel, M.; Xu, K.; et al. 17beta-hydroxysteroid dehydrogenases (17beta-hsds) as therapeutic targets: Protein structures, functions, and recent progress in inhibitor development. J. Steroid Biochem. Mol. Biol. 2011, 125, 66-82. [CrossRef] [PubMed]

54. Koch, M.A.; Wittenberg, L.O.; Basu, S.; Jeyaraj, D.A.; Gourzoulidou, E.; Reinecke, K.; Odermatt, A.; Waldmann, H. Compound library development guided by protein structure similarity clustering and natural product structure. Proc. Natl. Acad. Sci. USA 2004, 101, 16721-16726. [CrossRef] [PubMed]

55. Koch, M.A.; Schuffenhauer, A.; Scheck, M.; Wetzel, S.; Casaulta, M.; Odermatt, A.; Ertl, P.; Waldmann, H. Charting biologically relevant chemical space: A structural classification of natural products (sconp). Proc. Natl. Acad. Sci. USA 2005, 102, 17272-17277. [CrossRef] [PubMed]

56. Guasch, L.; Sala, E.; Castell-Auví, A.; Cedó, L.; Liedl, K.R.; Wolber, G.; Muehlbacher, M.; Mulero, M.; Pinent, M.; Ardévol, A.; et al. Identification of ppargamma partial agonists of natural origin (i): Development of a virtual screening procedure and in vitro validation. PLoS ONE 2012, 7, e50816. [CrossRef] [PubMed]

57. Lipinski, C.A.; Lombardo, F.; Dominy, B.W.; Feeney, P.J. Experimental and computational approaches to estimate solubility and permeability in drug discovery and development settings. Adv. Drug Deliv. Rev. 1997, 23, 3-25. [CrossRef]

58. Veber, D.F.; Johnson, S.R.; Cheng, H.-Y.; Smith, B.R.; Ward, K.W.; Kopple, K.D. Molecular properties that influence the oral bioavailability of drug candidates. J. Med. Chem. 2002, 45, 2615-2623. [CrossRef] [PubMed] 
59. Congreve, M.; Carr, R.; Murray, C.; Jhoti, H. A "rule of three" for fragment-based lead discovery? Drug Discov. Today 2003, 8, 876-877. [CrossRef]

60. Baell, J.B.; Holloway, G.A. New substructure filters for removal of pan assay interference compounds (pains) from screening libraries and for their exclusion in bioassays. J. Chem. Med. 2010, 53, 2719-2740. [CrossRef] [PubMed]

61. Baell, J.; Walters, M.A. Chemistry: Chemical con artists foil drug discovery. Nature 2014, 513, 481-483. [CrossRef] [PubMed]

62. Noha, S.M.; Fischer, K.; Koeberle, A.; Garscha, U.; Werz, O.; Schuster, D. Discovery of novel, non-acidic mPGES-1 inhibitors by virtual screening with a multistep protocol. Bioorganic Med. Chem. 2015, 23, 4839-4845. [CrossRef] [PubMed]

63. Kavanagh, K.L.; Jornvall, H.; Persson, B.; Oppermann, U. Medium- and short-chain dehydrogenase/reductase gene and protein families: The SDR superfamily: Functional and structural diversity within a family of metabolic and regulatory enzymes. Cell. Mol. Life Sci. 2008, 65, 3895-3906. [CrossRef] [PubMed]

64. Miller, W.L.; Auchus, R.J. The molecular biology, biochemistry, and physiology of human steroidogenesis and its disorders. Endocr. Rev. 2011, 32, 81-151. [CrossRef] [PubMed]

65. Yang, S.Y.; He, X.Y.; Isaacs, C.; Dobkin, C.; Miller, D.; Philipp, M. Roles of 17 $\beta$-hydroxysteroid dehydrogenase type 10 in neurodegenerative disorders. J. Steroid Biochem. Mol. Biol. 2014, 143, 460-472. [CrossRef] [PubMed]

66. Gathercole, L.L.; Lavery, G.G.; Morgan, S.A.; Cooper, M.S.; Sinclair, A.J.; Tomlinson, J.W.; Stewart, P.M. 11ß-hydroxysteroid dehydrogenase 1: Translational and therapeutic aspects. Endocr. Rev. 2013, 34, 525-555. [CrossRef] [PubMed]

67. Luu-The, V. Assessment of steroidogenesis and steroidogenic enzyme functions. J. Steroid Biochem. Mol. Biol. 2013, 137, 176-182. [CrossRef] [PubMed]

68. Vuorinen, A.; Odermatt, A.; Schuster, D. In silico methods in the discovery of endocrine disrupting chemicals. J. Steroid Biochem. Mol. Biol. 2013, 137, 18-26. [CrossRef] [PubMed]

69. Vitku, J.; Starka, L.; Bicikova, M.; Hill, M.; Heracek, J.; Sosvorova, L.; Hampl, R. Endocrine disruptors and other inhibitors of 11 $\beta$-hydroxysteroid dehydrogenase 1 and 2: Tissue-specific consequences of enzyme inhibition. J. Steroid Biochem. Mol. Biol. 2016, 155, 207-216. [CrossRef] [PubMed]

70. Nashev, L.G.; Vuorinen, A.; Praxmarer, L.; Chantong, B.; Cereghetti, D.; Winiger, R.; Schuster, D.; Odermatt, A. Virtual screening as a strategy for the identification of xenobiotics disrupting corticosteroid action. PLoS ONE 2012, 7, e46958. [CrossRef] [PubMed]

71. Odermatt, A.; Nashev, L.G. The glucocorticoid-activating enzyme $11 \beta$-hydroxysteroid dehydrogenase type 1 has broad substrate specificity: Physiological and toxicological considerations. J. Steroid Biochem. Mol. Biol. 2010, 119, 1-13. [CrossRef] [PubMed]

72. Maser, E.; Oppermann, U.C. Role of type-1 11ß-hydroxysteroid dehydrogenase in detoxification processes. Eur. J. Biochem. 1997, 249, 365-369. [CrossRef] [PubMed]

73. Maser, E. Xenobiotic carbonyl reduction and physiological steroid oxidoreduction. The pluripotency of several hydroxysteroid dehydrogenases. Biochem. Pharmacol. 1995, 49, 421-440. [CrossRef]

74. Nashev, L.G.; Schuster, D.; Laggner, C.; Sodha, S.; Langer, T.; Wolber, G.; Odermatt, A. The uv-filter benzophenone-1 inhibits $17 \beta$-hydroxysteroid dehydrogenase type 3: Virtual screening as a strategy to identify potential endocrine disrupting chemicals. Biochem. Pharmacol. 2010, 79, 1189-1199. [CrossRef] [PubMed]

75. Yuan, K.; Zhao, B.; Li, X.W.; Hu, G.X.; Su, Y.; Chu, Y.; Akingbemi, B.T.; Lian, Q.Q.; Ge, R.S. Effects of phthalates on $3 \beta$-hydroxysteroid dehydrogenase and 17beta-hydroxysteroid dehydrogenase 3 activities in human and rat testes. Chem.-Biol. Interact. 2012, 195, 180-188. [CrossRef] [PubMed]

76. Zhao, B.; Chu, Y.; Hardy, D.O.; Li, X.K.; Ge, R.S. Inhibition of $3 \beta$ - and $17 \beta$-hydroxysteroid dehydrogenase activities in rat leydig cells by perfluorooctane acid. J. Steroid Biochem. Mol. Biol. 2009, 118, 13-17. [CrossRef] [PubMed]

77. Chapman, K.; Holmes, M.; Seckl, J. 11beta-hydroxysteroid dehydrogenases: Intracellular gate-keepers of tissue glucocorticoid action. Physiol. Rev. 2013, 93, 1139-1206. [CrossRef] [PubMed]

78. Kratschmar, D.V.; Vuorinen, A.; Da Cunha, T.; Wolber, G.; Classen-Houben, D.; Doblhoff, O.; Schuster, D.; Odermatt, A. Characterization of activity and binding mode of glycyrrhetinic acid derivatives inhibiting 11beta-hydroxysteroid dehydrogenase type 2. J. Steroid Biochem. Mol. Biol. 2011, 125, 129-142. [CrossRef] [PubMed] 
79. Kannisto, K.; Pietilainen, K.H.; Ehrenborg, E.; Rissanen, A.; Kaprio, J.; Hamsten, A.; Yki-Jarvinen, H. Overexpression of $11 \beta$-hydroxysteroid dehydrogenase-1 in adipose tissue is associated with acquired obesity and features of insulin resistance: Studies in young adult monozygotic twins. J. Clin. Endocrinol. Metab. 2004, 89, 4414-4421. [CrossRef] [PubMed]

80. Kotelevtsev, Y.; Holmes, M.C.; Burchell, A.; Houston, P.M.; Schmoll, D.; Jamieson, P.; Best, R.; Brown, R.; Edwards, C.R.; Seckl, J.R.; et al. 11beta-hydroxysteroid dehydrogenase type 1 knockout mice show attenuated glucocorticoid-inducible responses and resist hyperglycemia on obesity or stress. Proc. Natl. Acad. Sci. USA 1997, 94, 14924-14929. [CrossRef] [PubMed]

81. Lindsay, R.S.; Wake, D.J.; Nair, S.; Bunt, J.; Livingstone, D.E.; Permana, P.A.; Tataranni, P.A.; Walker, B.R. Subcutaneous adipose 11 $\beta$-hydroxysteroid dehydrogenase type 1 activity and messenger ribonucleic acid levels are associated with adiposity and insulinemia in pima indians and caucasians. J. Clin. Endocrinol. Metab. 2003, 88, 2738-2744. [CrossRef] [PubMed]

82. Masuzaki, H.; Paterson, J.; Shinyama, H.; Morton, N.M.; Mullins, J.J.; Seckl, J.R.; Flier, J.S. A transgenic model of visceral obesity and the metabolic syndrome. Science 2001, 294, 2166-2170. [CrossRef] [PubMed]

83. Masuzaki, H.; Yamamoto, H.; Kenyon, C.J.; Elmquist, J.K.; Morton, N.M.; Paterson, J.M.; Shinyama, H.; Sharp, M.G.; Fleming, S.; Mullins, J.J.; et al. Transgenic amplification of glucocorticoid action in adipose tissue causes high blood pressure in mice. J. Clin. Investig. 2003, 112, 83-90. [CrossRef] [PubMed]

84. Paterson, J.M.; Morton, N.M.; Fievet, C.; Kenyon, C.J.; Holmes, M.C.; Staels, B.; Seckl, J.R.; Mullins, J.J. Metabolic syndrome without obesity: Hepatic overexpression of $11 \beta$-hydroxysteroid dehydrogenase type 1 in transgenic mice. Proc. Natl. Acad. Sci. USA 2004, 101, 7088-7093. [CrossRef] [PubMed]

85. Paulmyer-Lacroix, O.; Boullu, S.; Oliver, C.; Alessi, M.C.; Grino, M. Expression of the mRNA coding for $11 \beta$-hydroxysteroid dehydrogenase type 1 in adipose tissue from obese patients: An in situ hybridization study. J. Clin. Endocrinol. Metab. 2002, 87, 2701-2705. [CrossRef] [PubMed]

86. Rask, E.; Walker, B.R.; Soderberg, S.; Livingstone, D.E.; Eliasson, M.; Johnson, O.; Andrew, R.; Olsson, T. Tissue-specific changes in peripheral cortisol metabolism in obese women: Increased adipose 11ß-hydroxysteroid dehydrogenase type 1 activity. J. Clin. Endocrinol. Metab. 2002, 87, 3330-3336. [CrossRef] [PubMed]

87. Valsamakis, G.; Anwar, A.; Tomlinson, J.W.; Shackleton, C.H.; McTernan, P.G.; Chetty, R.; Wood, P.J.; Banerjee, A.K.; Holder, G.; Barnett, A.H.; et al. 11 $\beta$-hydroxysteroid dehydrogenase type 1 activity in lean and obese males with type 2 diabetes mellitus. J. Clin. Endocrinol. Metab. 2004, 89, 4755-4761. [CrossRef] [PubMed]

88. Kipari, T.; Hadoke, P.W.; Iqbal, J.; Man, T.Y.; Miller, E.; Coutinho, A.E.; Zhang, Z.; Sullivan, K.M.; Mitic, T.; Livingstone, D.E.; et al. 11 $\beta$-hydroxysteroid dehydrogenase type 1 deficiency in bone marrow-derived cells reduces atherosclerosis. FASEB J. 2013, 27, 1519-1531. [CrossRef] [PubMed]

89. Hermanowski-Vosatka, A.; Balkovec, J.M.; Cheng, K.; Chen, H.Y.; Hernandez, M.; Koo, G.C.; Le Grand, C.B.; Li, Z.; Metzger, J.M.; Mundt, S.S.; et al. 11ß-HSD1 inhibition ameliorates metabolic syndrome and prevents progression of atherosclerosis in mice. J. Exp. Med. 2005, 202, 517-527. [CrossRef] [PubMed]

90. Garcia, R.A.; Search, D.J.; Lupisella, J.A.; Ostrowski, J.; Guan, B.; Chen, J.; Yang, W.P.; Truong, A.; He, A.; Zhang, R.; et al. 11 $\beta$-hydroxysteroid dehydrogenase type 1 gene knockout attenuates atherosclerosis and in vivo foam cell formation in hyperlipidemic apoe ${ }^{-} /^{-}$mice. PLoS ONE 2013, 8, e53192. [CrossRef] [PubMed]

91. Luo, M.J.; Thieringer, R.; Springer, M.S.; Wright, S.D.; Hermanowski-Vosatka, A.; Plump, A.; Balkovec, J.M.; Cheng, K.; Ding, G.J.; Kawka, D.W.; et al. 11ß-HSD1 inhibition reduces atherosclerosis in mice by altering proinflammatory gene expression in the vasculature. Physiol. Genom. 2013, 45, 47-57. [CrossRef] [PubMed]

92. Wu, L.; Qi, H.; Zhong, Y.; Lv, S.; Yu, J.; Liu, J.; Wang, L.; Bi, J.; Kong, X.; Di, W.; et al. 11ß-hydroxysteroid dehydrogenase type 1 selective inhibitor bvt.2733 protects osteoblasts against endogenous glucocorticoid induced dysfunction. Endocr. J. 2013, 60, 1047-1058. [CrossRef] [PubMed]

93. Rauz, S.; Cheung, C.M.; Wood, P.J.; Coca-Prados, M.; Walker, E.A.; Murray, P.I.; Stewart, P.M. Inhibition of $11 \beta$-hydroxysteroid dehydrogenase type 1 lowers intraocular pressure in patients with ocular hypertension. QJM 2003, 96, 481-490. [CrossRef] [PubMed]

94. Rauz, S.; Walker, E.A.; Shackleton, C.H.; Hewison, M.; Murray, P.I.; Stewart, P.M. Expression and putative role of $11 \beta$-hydroxysteroid dehydrogenase isozymes within the human eye. Investig. Ophthalmol. Visual Sci. 2001, 42, 2037-2042. 
95. Anderson, S.; Carreiro, S.; Quenzer, T.; Gale, D.; Xiang, C.; Gukasyan, H.; Lafontaine, J.; Cheng, H.; Krauss, A.; Prasanna, G. In vivo evaluation of $11 \beta$-hydroxysteroid dehydrogenase activity in the rabbit eye. J. Ocul. Pharmacol. Ther. 2009, 25, 215-222. [CrossRef] [PubMed]

96. Sooy, K.; Webster, S.P.; Noble, J.; Binnie, M.; Walker, B.R.; Seckl, J.R.; Yau, J.L. Partial deficiency or short-term inhibition of $11 \beta$-hydroxysteroid dehydrogenase type 1 improves cognitive function in aging mice. J. Neurosci. 2010, 30, 13867-13872. [CrossRef] [PubMed]

97. Yau, J.L.; McNair, K.M.; Noble, J.; Brownstein, D.; Hibberd, C.; Morton, N.; Mullins, J.J.; Morris, R.G.; Cobb, S.; Seckl, J.R. Enhanced hippocampal long-term potentiation and spatial learning in aged $11 \beta$-hydroxysteroid dehydrogenase type 1 knock-out mice. J. Neurosci. 2007, 27, 10487-10496. [CrossRef] [PubMed]

98. Yau, J.L.; Noble, J.; Seckl, J.R. 11ß-hydroxysteroid dehydrogenase type 1 deficiency prevents memory deficits with aging by switching from glucocorticoid receptor to mineralocorticoid receptor-mediated cognitive control. J. Neurosci. 2011, 31, 4188-4193. [CrossRef] [PubMed]

99. Sooy, K.; Noble, J.; McBride, A.; Binnie, M.; Yau, J.L.; Seckl, J.R.; Walker, B.R.; Webster, S.P. Cognitive and disease-modifying effects of 11ss-hydroxysteroid dehydrogenase type 1 inhibition in male tg2576 mice, a model of Alzheimer's disease. Endocrinology 2015, 156, 4592-4603. [CrossRef] [PubMed]

100. Mohler, E.G.; Browman, K.E.; Roderwald, V.A.; Cronin, E.A.; Markosyan, S.; Scott Bitner, R.; Strakhova, M.I.; Drescher, K.U.; Hornberger, W.; Rohde, J.J.; et al. Acute inhibition of 11ß-hydroxysteroid dehydrogenase type-1 improves memory in rodent models of cognition. J. Neurosci. 2011, 31, 5406-5413. [CrossRef] [PubMed]

101. Tiganescu, A.; Tahrani, A.A.; Morgan, S.A.; Otranto, M.; Desmouliere, A.; Abrahams, L.; Hassan-Smith, Z.; Walker, E.A.; Rabbitt, E.H.; Cooper, M.S.; et al. 11ß-hydroxysteroid dehydrogenase blockade prevents age-induced skin structure and function defects. J. Clin. Investig. 2013, 123, 3051-3060. [CrossRef] [PubMed]

102. Tiganescu, A.; Hupe, M.; Uchida, Y.; Mauro, T.; Elias, P.M.; Holleran, W.M. Increased glucocorticoid activation during mouse skin wound healing. J. Endocrinol. 2014, 221, 51-61. [CrossRef] [PubMed]

103. Youm, J.K.; Park, K.; Uchida, Y.; Chan, A.; Mauro, T.M.; Holleran, W.M.; Elias, P.M. Local blockade of glucocorticoid activation reverses stress- and glucocorticoid-induced delays in cutaneous wound healing. Wound Repair Regen. 2013, 21, 715-722. [CrossRef] [PubMed]

104. Scott, J.S.; Goldberg, F.W.; Turnbull, A.V. Medicinal chemistry of inhibitors of $11 \beta$-hydroxysteroid dehydrogenase type 1 (11ß-HSD1). J. Med. Chem. 2014, 57, 4466-4486. [CrossRef] [PubMed]

105. Thomas, M.P.; Potter, B.V. Crystal structures of 11beta-hydroxysteroid dehydrogenase type 1 and their use in drug discovery. Future Med. Chem. 2011, 3, 367-390. [CrossRef] [PubMed]

106. Schuster, D.; Maurer, E.M.; Laggner, C.; Nashev, L.G.; Wilckens, T.; Langer, T.; Odermatt, A. The discovery of new $11 \beta$-hydroxysteroid dehydrogenase type 1 inhibitors by common feature pharmacophore modeling and virtual screening. J. Med. Chem. 2006, 49, 3454-3466. [CrossRef] [PubMed]

107. Hofer, S.; Kratschmar, D.V.; Schernthanner, B.; Vuorinen, A.; Schuster, D.; Odermatt, A.; Easmon, J. Synthesis and biological analysis of benzazol-2-yl piperazine sulfonamides as $11 \beta$-hydroxysteroid dehydrogenase 1 inhibitors. Bioorg. Med. Chem. Lett. 2013, 23, 5397-5400. [CrossRef] [PubMed]

108. Rollinger, J.M.; Kratschmar, D.V.; Schuster, D.; Pfisterer, P.H.; Gumy, C.; Aubry, E.M.; Brandstötter, S.; Stuppner, H.; Wolber, G.; Odermatt, A. 11ß-hydroxysteroid dehydrogenase 1 inhibiting constituents from eriobotrya japonica revealed by bioactivity-guided isolation and computational approaches. Bioorganic Med. Chem. 2010, 18, 1507-1515. [CrossRef] [PubMed]

109. Gumy, C.; Thurnbichler, C.; Aubry, E.M.; Balazs, Z.; Pfisterer, P.; Baumgartner, L.; Stuppner, H.; Odermatt, A.; Rollinger, J.M. Inhibition of $11 \beta$-hydroxysteroid dehydrogenase type 1 by plant extracts used as traditional antidiabetic medicines. Fitoterapia 2009. [CrossRef] [PubMed]

110. Wu, X.; Kavanagh, K.; Svensson, S.; Elleby, B.; Hult, M.; Von Delft, F.; Marsden, B.; Jornvall, H.; Abrahmsen, L.; Oppermann, U. Structure of human $11 \beta$-hydroxysteroid dehydrogenase in complex with nadp and carbenoxolone. PDB Entry 2BEL 2004. [CrossRef]

111. Vuorinen, A.; Seibert, J.; Papageorgiou, V.P.; Rollinger, J.M.; Odermatt, A.; Schuster, D.; Assimopoulou, A.N. Pistacia lentiscus oleoresin: Virtual screening and identification of masticadienonic and isomasticadienonic acids as inhibitors of $11 \beta$-hydroxysteroid dehydrogenase 1. Planta Med. 2015, 81, 525-532. [CrossRef] [PubMed] 
112. Yang, H.; Dou, W.; Lou, J.; Leng, Y.; Shen, J. Discovery of novel inhibitors of $11 \beta$-hydroxysteroid dehydrogenase type 1 by docking and pharmacophore modeling. Bioorg. Med. Chem. Lett. 2008, 18, 1340-1345. [CrossRef] [PubMed]

113. Hosfield, D.J.; Wu, Y.; Skene, R.J.; Hilgers, M.; Jennings, A.; Snell, G.P.; Aertgeerts, K. Conformational flexibility in crystal structures of human $11 \beta$-hydroxysteroid dehydrogenase type i provide insights into glucocorticoid interconversion and enzyme regulation. J. Biol. Chem. 2005, 280, 4639-4648. [CrossRef] [PubMed]

114. Ewing, T.J.A.; Makino, S.; Skillman, A.G.; Kuntz, I.D. DOCK 4.0: Search strategies for automated molecular docking of flexible molecule databases. J. Comput.-Aided Mol. Des. 2001, 15, 411-428. [CrossRef] [PubMed]

115. Friesner, R.A.; Banks, J.L.; Murphy, R.B.; Halgren, T.A.; Klicic, J.J.; Mainz, D.T.; Repasky, M.P.; Knoll, E.H.; Shaw, D.E.; Shelley, M.; et al. Glide: A new approach for rapid, accurate docking and scoring. 1. Method and assessment of docking accuracy. J. Med. Chem. 2004, 47, 1739-1749. [CrossRef] [PubMed]

116. Catalyst Version 4.10; Accelrys Software Inc.: San Diego, CA, USA, 2005.

117. Arampatzis, S.; Kadereit, B.; Schuster, D.; Balazs, Z.; Schweizer, R.A.; Frey, F.J.; Langer, T.; Odermatt, A. Comparative enzymology of $11 \beta$-hydroxysteroid dehydrogenase type 1 from six species. J. Mol. Endocrinol. 2005, 35, 89-101. [CrossRef] [PubMed]

118. Barf, T.; Vallgarda, J.; Emond, R.; Haggstrom, C.; Kurz, G.; Nygren, A.; Larwood, V.; Mosialou, E.; Axelsson, K.; Olsson, R.; et al. Arylsulfonamidothiazoles as a new class of potential antidiabetic drugs. Discovery of potent and selective inhibitors of the 11beta-hydroxysteroid dehydrogenase type 1. J. Med. Chem. 2002, 45, 3813-3815. [CrossRef] [PubMed]

119. Yang, H.; Shen, Y.; Chen, J.; Jiang, Q.; Leng, Y.; Shen, J. Structure-based virtual screening for identification of novel 11ß-HSD1 inhibitors. Eur. J. Med. Chem. 2009, 44, 1167-1171. [CrossRef] [PubMed]

120. Moeller, G.; Adamski, J. Integrated view on $17 \beta$-hydroxysteroid dehydrogenases. Mol. Cell. Endocrinol. 2009, 301, 7-19. [CrossRef] [PubMed]

121. Poirier, D. Inhibitors of $17 \beta$-hydroxysteroid dehydrogenases. Curr. Med. Chem. 2003, 10, 453-477. [CrossRef] [PubMed]

122. Lukacik, P.; Kavanagh, K.L.; Oppermann, U. Structure and function of human 17 $\beta$-hydroxysteroid dehydrogenases. Mol. Cell. Endocrinol. 2006, 248, 61-71. [CrossRef] [PubMed]

123. Jansson, A. 17ß-hydroxysteroid dehydrogenase enzymes and breast cancer. J. Steroid Biochem. Mol. Biol. 2009, 114, 64-67. [CrossRef] [PubMed]

124. Oduwole, O.O.; Li, Y.; Isomaa, V.V.; Mantyniemi, A.; Pulkka, A.E.; Soini, Y.; Vihko, P.T. 17ß-hydroxysteroid dehydrogenase type 1 is an independent prognostic marker in breast cancer. Cancer Res. 2004, 64, 7604-7609. [CrossRef] [PubMed]

125. Miyoshi, Y.; Ando, A.; Shiba, E.; Taguchi, T.; Tamaki, Y.; Noguchi, S. Involvement of up-regulation of $17 \beta$-hydroxysteroid dehydrogenase type 1 in maintenance of intratumoral high estradiol levels in postmenopausal breast cancers. Int. J. Cancer 2001, 94, 685-689. [CrossRef] [PubMed]

126. Smuc, T.; Pucelj, M.R.; Sinkovec, J.; Husen, B.; Thole, H.; Rizner, T.L. Expression analysis of the genes involved in estradiol and progesterone action in human ovarian endometriosis. Gynecol. Endocrinol. 2007, 23, 105-111. [CrossRef] [PubMed]

127. Cornel, K.M.; Kruitwagen, R.F.; Delvoux, B.; Visconti, L.; van de Vijver, K.K.; Day, J.M.; van Gorp, T.; Hermans, R.J.; Dunselman, G.A.; Romano, A. Overexpression of $17 \beta$-hydroxysteroid dehydrogenase type 1 increases the exposure of endometrial cancer to 17ß-estradiol. J. Clin. Endocrinol. Metab. 2012, 97, E591-E601. [CrossRef] [PubMed]

128. Kasai, T.; Shozu, M.; Murakami, K.; Segawa, T.; Shinohara, K.; Nomura, K.; Inoue, M. Increased expression of type i $17 \beta$-hydroxysteroid dehydrogenase enhances in situ production of estradiol in uterine leiomyoma. J. Clin. Endocrinol. Metab. 2004, 89, 5661-5668. [CrossRef] [PubMed]

129. Hoffren, A.M.; Murray, C.M.; Hoffmann, R.D. Structure-based focusing using pharmacophores derived from the active site of 17ß-hydroxysteroid dehydrogenase. Curr. Pharm. Des. 2001, 7, 547-566. [CrossRef] [PubMed]

130. Krazeisen, A.; Breitling, R.; Moller, G.; Adamski, J. Phytoestrogens inhibit human $17 \beta$-hydroxysteroid dehydrogenase type 5. Mol. Cell. Endocrinol. 2001, 171, 151-162. [CrossRef]

131. Berube, M.; Poirier, D. Synthesis of simplified hybrid inhibitors of type $117 \beta$-hydroxysteroid dehydrogenase via cross-metathesis and sonogashira coupling reactions. Org. Lett. 2004, 6, 3127-3130. [CrossRef] [PubMed] 
132. Fournier, D.; Poirier, D.; Mazumdar, M.; Lin, S.X. Design and synthesis of bisubstrate inhibitors of type 1 17 $\beta$-hydroxysteroid dehydrogenase: Overview and perspectives. Eur. J. Med. Chem. 2008, 43, 2298-2306. [CrossRef] [PubMed]

133. Schuster, D.; Nashev, L.G.; Kirchmair, J.; Laggner, C.; Wolber, G.; Langer, T.; Odermatt, A. Discovery of nonsteroidal $17 \beta$-hydroxysteroid dehydrogenase 1 inhibitors by pharmacophore-based screening of virtual compound libraries. J. Med. Chem. 2008, 51, 4188-4199. [CrossRef] [PubMed]

134. Spadaro, A.; Negri, M.; Marchais-Oberwinkler, S.; Bey, E.; Frotscher, M. Hydroxybenzothiazoles as new nonsteroidal inhibitors of 17beta-hydroxysteroid dehydrogenase type 1 (17 $\beta$-HSD1). PLOS ONE 2012, 7, e29252. [CrossRef] [PubMed]

135. Spadaro, A.; Frotscher, M.; Hartmann, R.W. Optimization of hydroxybenzothiazoles as novel potent and selective inhibitors of 17 $\beta$-HSD1. J. Med. Chem. 2012, 55, 2469-2473. [CrossRef] [PubMed]

136. Karkola, S.; Alho-Richmond, S.; Wahala, K. Pharmacophore modelling of 17 $\beta$-HSD1 enzyme based on active inhibitors and enzyme structure. Mol. Cell. Endocrinol. 2009, 301, 225-228. [CrossRef] [PubMed]

137. Wu, L.; Einstein, M.; Geissler, W.M.; Chan, H.K.; Elliston, K.O.; Andersson, S. Expression cloning and characterization of human $17 \beta$-hydroxysteroid dehydrogenase type 2, a microsomal enzyme possessing 20 $\alpha$-hydroxysteroid dehydrogenase activity. J. Biol. Chem. 1993, 268, 12964-12969. [PubMed]

138. Puranen, T.J.; Kurkela, R.M.; Lakkakorpi, J.T.; Poutanen, M.H.; Itaranta, P.V.; Melis, J.P.; Ghosh, D.; Vihko, R.K.; Vihko, P.T. Characterization of molecular and catalytic properties of intact and truncated human 17 $\beta$-hydroxysteroid dehydrogenase type 2 enzymes: Intracellular localization of the wild-type enzyme in the endoplasmic reticulum. Endocrinology 1999, 140, 3334-3341. [CrossRef] [PubMed]

139. Dong, Y.; Qiu, Q.Q.; Debear, J.; Lathrop, W.F.; Bertolini, D.R.; Tamburini, P.P. 17ß-hydroxysteroid dehydrogenases in human bone cells. J. Bone Miner. Res. 1998, 13, 1539-1546. [CrossRef] [PubMed]

140. Vihko, P.; Isomaa, V.; Ghosh, D. Structure and function of $17 \beta$-hydroxysteroid dehydrogenase type 1 and type 2. Mol. Cell. Endocrinol. 2001, 171, 71-76. [CrossRef]

141. Vuorinen, A.; Engeli, R.; Meyer, A.; Bachmann, F.; Griesser, U.J.; Schuster, D.; Odermatt, A. Ligand-based pharmacophore modeling and virtual screening for the discovery of novel 17 $\beta$-hydroxysteroid dehydrogenase 2 inhibitors. J. Med. Chem. 2014, 57, 5995-6007. [CrossRef] [PubMed]

142. Geissler, W.M.; Davis, D.L.; Wu, L.; Bradshaw, K.D.; Patel, S.; Mendonca, B.B.; Elliston, K.O.; Wilson, J.D.; Russell, D.W.; Andersson, S. Male pseudohermaphroditism caused by mutations of testicular 17ß-hydroxysteroid dehydrogenase 3. Nat. Genet. 1994, 7, 34-39. [CrossRef] [PubMed]

143. Koh, E.; Noda, T.; Kanaya, J.; Namiki, M. Differential expression of $17 \beta$-hydroxysteroid dehydrogenase isozyme genes in prostate cancer and noncancer tissues. Prostate 2002, 53, 154-159. [CrossRef] [PubMed]

144. Legeza, B.; Balazs, Z.; Nashev, L.G.; Odermatt, A. The microsomal enzyme 17ß-hydroxysteroid dehydrogenase 3 faces the cytoplasm and uses NADPH generated by glucose-6-phosphate dehydrogenase. Endocrinology 2013, 154, 205-213. [CrossRef] [PubMed]

145. Tsachaki, M.; Birk, J.; Egert, A.; Odermatt, A. Determination of the topology of endoplasmic reticulum membrane proteins using redox-sensitive green-fluorescence protein fusions. Biochim. Biophys. Acta 2015, 1853, 1672-1682. [CrossRef] [PubMed]

146. Schuster, D.; Kowalik, D.; Kirchmair, J.; Laggner, C.; Markt, P.; Aebischer-Gumy, C.; Strohle, F.; Moller, G.; Wolber, G.; Wilckens, T.; et al. Identification of chemically diverse, novel inhibitors of $17 \beta$-hydroxysteroid dehydrogenase type 3 and 5 by pharmacophore-based virtual screening. J. Steroid Biochem. Mol. Biol. 2011, 125, 148-161. [CrossRef] [PubMed]

147. Vicker, N.; Sharland, C.M.; Heaton, W.B.; Gonzalez, A.M.; Bailey, H.V.; Smith, A.; Springall, J.S.; Day, J.M.; Tutill, H.J.; Reed, M.J.; et al. The design of novel 17 $\beta$-hydroxysteroid dehydrogenase type 3 inhibitors. Mol. Cell. Endocrinol. 2009, 301, 259-265. [CrossRef] [PubMed]

148. Kratz, J.M.; Schuster, D.; Edtbauer, M.; Saxena, P.; Mair, C.E.; Kirchebner, J.; Matuszczak, B.; Baburin, I.; Hering, S.; Rollinger, J.M. Experimentally validated herg pharmacophore models as cardiotoxicity prediction tools. J. Chem. Inf. Model. 2014, 54, 2887-2901. [CrossRef] [PubMed]

149. Duwensee, K.; Schwaiger, S.; Tancevski, I.; Eller, K.; van Eck, M.; Markt, P.; Linder, T.; Stanzl, U.; Ritsch, A.; Patsch, J.R.; et al. Leoligin, the major lignan from edelweiss, activates cholesteryl ester transfer protein. Atherosclerosis 2011, 219, 109-115. [CrossRef] [PubMed] 
150. Kaserer, T.; Höferl, M.; Müller, K.; Elmer, S.; Ganzera, M.; Jäger, W.; Schuster, D. In silico predictions of drug-drug interactions caused by cyp1a2, 2c9, and 3a4 inhibition-A comparative study of virtual screening performance. Mol. Inf. 2015, 34, 431-457. [CrossRef]

151. Blumberg, B.; Iguchi, T.; Odermatt, A. Endocrine disrupting chemicals. J. Steroid Biochem. Mol. Biol. 2011, 127, 1-3. [CrossRef] [PubMed]

152. Hampl, R.; Kubatova, J.; Starka, L. Steroids and endocrine disruptors-history, recent state of art and open questions. J. Steroid Biochem. Mol. Biol. 2016, 155, 217-223. [CrossRef] [PubMed]

153. Mune, T.; Rogerson, F.M.; Nikkila, H.; Agarwal, A.K.; White, P.C. Human hypertension caused by mutations in the kidney isozyme of 11ß-hydroxysteroid dehydrogenase. Nat. Genet. 1995, 10, 394-399. [CrossRef] [PubMed]

154. Wilson, R.C.; Harbison, M.D.; Krozowski, Z.S.; Funder, J.W.; Shackleton, C.H.L.; Hanauskeabel, H.M.; Wei, J.Q.; Hertecant, J.; Moran, A.; Neiberger, R.E.; et al. Several homozygous mutations in the gene for $11 \beta$-hydroxysteroid dehydrogenase type-2 in patients with apparent mineralocorticoid excess. J. Clin. Endocrinol. Metab. 1995, 80, 3145-3150. [PubMed]

155. Lindsay, R.S.; Lindsay, R.M.; Edwards, C.R.; Seckl, J.R. Inhibition of 11ß-hydroxysteroid dehydrogenase in pregnant rats and the programming of blood pressure in the offspring. Hypertension 1996, 27, 1200-1204. [CrossRef] [PubMed]

156. Nyirenda, M.J.; Lindsay, R.S.; Kenyon, C.J.; Burchell, A.; Seckl, J.R. Glucocorticoid exposure in late gestation permanently programs rat hepatic phosphoenolpyruvate carboxykinase and glucocorticoid receptor expression and causes glucose intolerance in adult offspring. J. Clin. Investig. 1998, 101, 2174-2181. [CrossRef] [PubMed]

157. Boehmer, A.L.; Brinkmann, A.O.; Sandkuijl, L.A.; Halley, D.J.; Niermeijer, M.F.; Andersson, S.; de Jong, F.H.; Kayserili, H.; de Vroede, M.A.; Otten, B.J.; et al. 17 $\beta$-hydroxysteroid dehydrogenase-3 deficiency: Diagnosis, phenotypic variability, population genetics, and worldwide distribution of ancient and de novo mutations. J. Clin. Endocrinol. Metab. 1999, 84, 4713-4721. [CrossRef] [PubMed]

158. Phelan, N.; Williams, E.L.; Cardamone, S.; Lee, M.; Creighton, S.M.; Rumsby, G.; Conway, G.S. Screening for mutations in $17 \beta$-hydroxysteroid dehydrogenase and androgen receptor in women presenting with partially virilised 46,xy disorders of sex development. Eur. J. Endocrinol. 2015, 172, 745-751. [CrossRef] [PubMed]

159. Wang, L.; Kannan, K. Characteristic profiles of benzonphenone-3 and its derivatives in urine of children and adults from the United States and China. Environ. Sci. Technol. 2013, 47, 12532-12538. [CrossRef] [PubMed]

160. Temml, V.; Kaserer, T.; Kutil, Z.; Landa, P.; Vanek, T.; Schuster, D. Pharmacophore modelling for cyclooxygenase- 1 and 2 inhibitors with ligandscout in comparison to discovery studio. Future Med. Chem. 2014, 6, 1869-1881. [CrossRef] [PubMed]

161. Dixon, S.; Smondyrev, A.; Knoll, E.; Rao, S.; Shaw, D.; Friesner, R. Phase: A new engine for pharmacophore perception, 3D QSAR model development, and 3D database screening: 1. Methodology and preliminary results. J. Comput.-Aided Mol. Des. 2006, 20, 647-671. [CrossRef] [PubMed]

162. Sirimulla, S.; Bailey, J.B.; Vegesna, R.; Narayan, M. Halogen interactions in protein-ligand complexes: Implications of halogen bonding for rational drug design. J. Chem. Inf. Model. 2013, 53, 2781-2791. [CrossRef] [PubMed]

163. Fourches, D.; Muratov, E.; Tropsha, A. Trust, but verify: On the importance of chemical structure curation in cheminformatics and qsar modeling research. J. Chem. Inf. Model. 2010, 50, 1189-1204. [CrossRef] [PubMed]

164. Scior, T.; Bender, A.; Tresadern, G.; Medina-Franco, J.L.; Martínez-Mayorga, K.; Langer, T.; Cuanalo-Contreras, K.; Agrafiotis, D.K. Recognizing pitfalls in virtual screening: A critical review. J. Chem. Inf. Model. 2012, 52, 867-881. [CrossRef] [PubMed]

(C) 2015 by the authors; licensee MDPI, Basel, Switzerland. This article is an open access article distributed under the terms and conditions of the Creative Commons by Attribution (CC-BY) license (http://creativecommons.org/licenses/by/4.0/). 